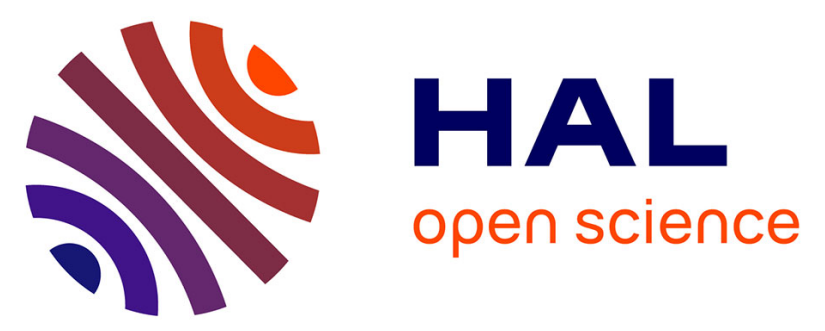

\title{
Synthesis, photophysical and electropolymerization properties of thiophene-substituted 2,3-diphenylbuta-1,3-dienes
}

Maxime Roger, Kassem Amro, Joëlle Rault-Berthelot, Mathias Quiot, Arie van Der Lee, Cyril Poriel, Sébastien Richeter, Sébastien Clément, Philippe Gerbier

\section{To cite this version:}

Maxime Roger, Kassem Amro, Joëlle Rault-Berthelot, Mathias Quiot, Arie van Der Lee, et al.. Synthesis, photophysical and electropolymerization properties of thiophene-substituted 2,3-diphenylbuta1,3-dienes. New Journal of Chemistry, 2020, 44 (29), pp.12556-12567. 10.1039/d0nj02382e . hal03002432

\section{HAL Id: hal-03002432}

\section{https://hal-univ-rennes1.archives-ouvertes.fr/hal-03002432}

Submitted on 12 Nov 2020

HAL is a multi-disciplinary open access archive for the deposit and dissemination of scientific research documents, whether they are published or not. The documents may come from teaching and research institutions in France or abroad, or from public or private research centers.
L'archive ouverte pluridisciplinaire HAL, est destinée au dépôt et à la diffusion de documents scientifiques de niveau recherche, publiés ou non, émanant des établissements d'enseignement et de recherche français ou étrangers, des laboratoires publics ou privés. 


\section{Synthesis, photophysical and electropolymerization properties of thiophene-substituted 2,3-diphenylbuta-1,3-dienes}

Maxime Roger, ${ }^{\mathrm{a}}$ Kassem Amro, ${ }^{\mathrm{a}}$ Joëlle Rault-Berthelot, ${ }^{\mathrm{a}}$ Mathias Quiot, ${ }^{\mathrm{a}}$ Arie Van der Lee, ${ }^{\mathrm{a}}$ Cyril Poriel, Sébastien Richeter, ${ }^{\mathrm{a}}$ Sébastien Clément ${ }^{*^{\mathrm{a}}}$ and Philippe Gerbier $*^{\mathrm{a}}$

a. ICGM, Univ. Montpellier, CNRS, ENSCM, Montpellier, France. E-mail:

sebastien.clement1@umontpellier.fr; philippe.gerbier@umontpellier.fr

b. Univ Rennes, CNRS, ISCR-UMR CNRS 6226, F-35000 Rennes, France.

c. Institut Européen des Membranes, IEM - UMR 5635, ENSCM, CNRS, Université de Montpellier, Montpellier, France

† Footnotes relating to the title and/or authors should appear here.

Electronic Supplementary Information (ESI) available: Characterization and crystal data for Sil-EDOT and DPBs derivatives. See DOI: 10.1039/x0xx00000x

A series of 2,3-diphenylbuta-1,3-dienes (DPBs) bearing thiophene (T-DPB), bithiophene (BTDPB) and ethylenedioxythiophene (EDOT-DPB) electropolymerizable units were prepared through desilylation reactions of the corresponding 3,4-diphenylsiloles derivatives. These DPBs derivatives exhibit remarkable different aggregation induced emission (AIE) or aggregation enhanced emission (AEE) behaviour depending on the strength of the molecular interactions occuring in the solid state. Indeed, T-DPB and EDOT-DPB were found to be good AIEgens while BT-DPB exhibited AEE behaviour. Finally, the electrochemical properties of these new materials were investigated revealing for all DPBs the occurrence of electropolymerization processes leading potentially to low band gap polymers.

\section{Introduction}

Luminogens with aggregation-induced emission (AIE) features (AIEgens) have been the subject of a large number of studies over the past two decades and continue to draw considerable attention due to their fascinating photophysical properties. ${ }^{1,2}$ Indeed, contrary to conventional organic fluorophores containing large planar aromatic rings whose fluorescence is drastically decreased or quenched in the aggregated or solid state due to aggregation-caused quenching ( $A C Q$ ) phenomenon, AIE fluorophores exhibit strong emission in the solid state or upon aggregation due to the restriction of intramolecular motions (RIM) which shut down the non-radiative 
relaxation pathway. ${ }^{3,4}$ In addition to this high solid-state emission, AIEgens are featured with large Stokes shift, high photostability, and low background noise in dilute solution. ${ }^{1,5}$ As such, the AIE effect has enabled to take advantage of the aggregation process and has triggered to new developments in an array of fields including bioimaging, ${ }^{6-9}$ therapy $^{10-12}$ chemosensing, ${ }^{13-16}$ optoelectronics ${ }^{17-18}$ and stimuli-responsive systems. ${ }^{19-23}$ Due to this dynamic research, a wide variety of AlEgens has been developed such as tetraphenylethylene $(T P E)^{24-26}$, silole ${ }^{27,28}$, quinoline malononitrile $(\mathrm{QM})^{29,30}$, triarylamine ${ }^{31-34}$, cyanostilbene ${ }^{35,36}$ or $9,10-$ distyrylanthracene (DSA) ${ }^{37,38}$ derivatives.

Buta-1,3-diene unit, which is prevalent in many biologically active natural compounds and pharmarceuticals, ${ }^{39-45}$ has recently emerged as an interesting conjugated building block for the design of AIE or aggregation-enhanced emission (AEE) luminophores, allowing to extend $\pi$-conjugation of $\mathrm{TPE}^{46}$. In this respect, multiphenyl-substituted 1,3-butadienes (MPBs) have recently received increasing attention $^{47,48}$. Noteworthy examples of this class of AIE (AEE) luminophores are 1,1,4,4-tetraphenylbuta-1,3-diene (TPB), a well-known highly efficient blue-emitting material $^{49-53}$ and 1,1,2,3,4,4-hexaphenylbuta-1,3-diene (HPB), which possess a helical structure like polyacetylene. ${ }^{54-56}$ Such MPBs exhibit multiple rotors in their structure and adopt twisted conformations allowing to avoid the presence of $\pi-\pi$ stacking interactions and thus, to minimize the possible formation of excimers. After the formation of the aggregates, the rotations are restricted leading to high emission efficiency. To extend the scope of the applications of these AIE (AEE) luminophores, synthetic efforts have been pursued to modify the nature of the aromatic groups and the substituent on the aromatic groups exploiting a wide range of synthetic strategies such as dienyl rearrangement ${ }^{57}$, alkaline desilylation ${ }^{58}$, allene isomerization ${ }^{59,60}$, aryne dimerization $^{46,61-64}$ and Suzuki coupling reactions between phenylboronic acid or its derivatives and bromo-substituted 1,4-diphenyl-1,3-butadienes. ${ }^{54,64,65}$

Despite these successful strategies, the development of new buta-1,3-dienebased building blocks whose optical properties (absorption/emission) can be tuned through judicious choice of the substituent linked to the 1,3-butadiene unit is still required. In this respect, we describe herein the synthesis of 2,3-diphenylbuta-1,3dienes (DPBs) bearing thienyl (T-DPB), bis-thienyl (BT-DPB) and EDOT (EDOT-DPB) 
units (see chemical structures in Scheme 2) through the desilylation of the corresponding silole derivatives (see chemical structures in Scheme 1). The presence of the bulky phenyl substituents at the 2,3-position helps to suppress potential intramolecular interactions which may improve their fluorescent properties, while the substituents attached at the 1,4-position enables increasing the conjugation length. ${ }^{50,}$ 58, 66 The choice of thienyl susbtituents was motivated by: i) their electron-rich character leading in general to significant bathochromic shifts in the absorption and emission spectra ${ }^{67-69}$, and ii) their ability to be polymerized allowing further modification of the optical characteristics of buta-1,3-diene through main-chain conjugation ${ }^{70-72}$. As such, these building blocks are both interesting in the form of small molecules and polymers and required further investigations. The study of the optical properties of these DPBs reveals an AIE or AEE behaviour with a strong increase of the fluorescence when aggregated. The electrochemical properties of these new materials were also evaluated revealing the formation of low band gap polymers through electropolymerization processes.

\section{Results and discussion}

\subsection{Synthesis and crystal structure of DPB derivatives}

DPBs bearing external thiophene (T), bithiophene (BT) or ethylenedioxythiophene (EDOT) units were synthesized in a two-step strategy. First, sil-T and sil-BT were prepared following reported literature procedure by using the method previously described by Tamao et al. (Scheme 1). ${ }^{58}$ Namely, silacyclopentadiene Sil-ZnCl was prepared in situ through the intramolecular reductive cyclization from dimethylbis(phenylethynyl)silane followed by the reaction with $\operatorname{dichloro}\left(N, N, N^{\prime}, N^{\prime}-\right.$ tetramethylethylenediamine)zinc ( $\left.\mathrm{ZnCl}_{2}-\mathrm{TMEDA}\right)$. Then, a Negishi coupling between this organozinc species and a 2-bromothienyl derivative was performed using $\mathrm{PdCl}_{2}\left(\mathrm{PPh}_{3}\right)_{2}$ as catalyst. Applying these conditions to sil-EDOT did not result in the formation of the desired compound. Alternatively, sil-EDOT was prepared by a Stille cross-coupling reaction between 1,1-dimethyl-2,5-dibromo-3,4-diphenylsilole (sil-Br) and 2 -stannyl-EDOT in THF in a $40 \%$ yield (Scheme 1$)^{73}$. sil-T and sil-BT can also be synthesized exploiting this strategy in $50 \%$ and $44 \%$ yields, respectively (Scheme 1 ). 


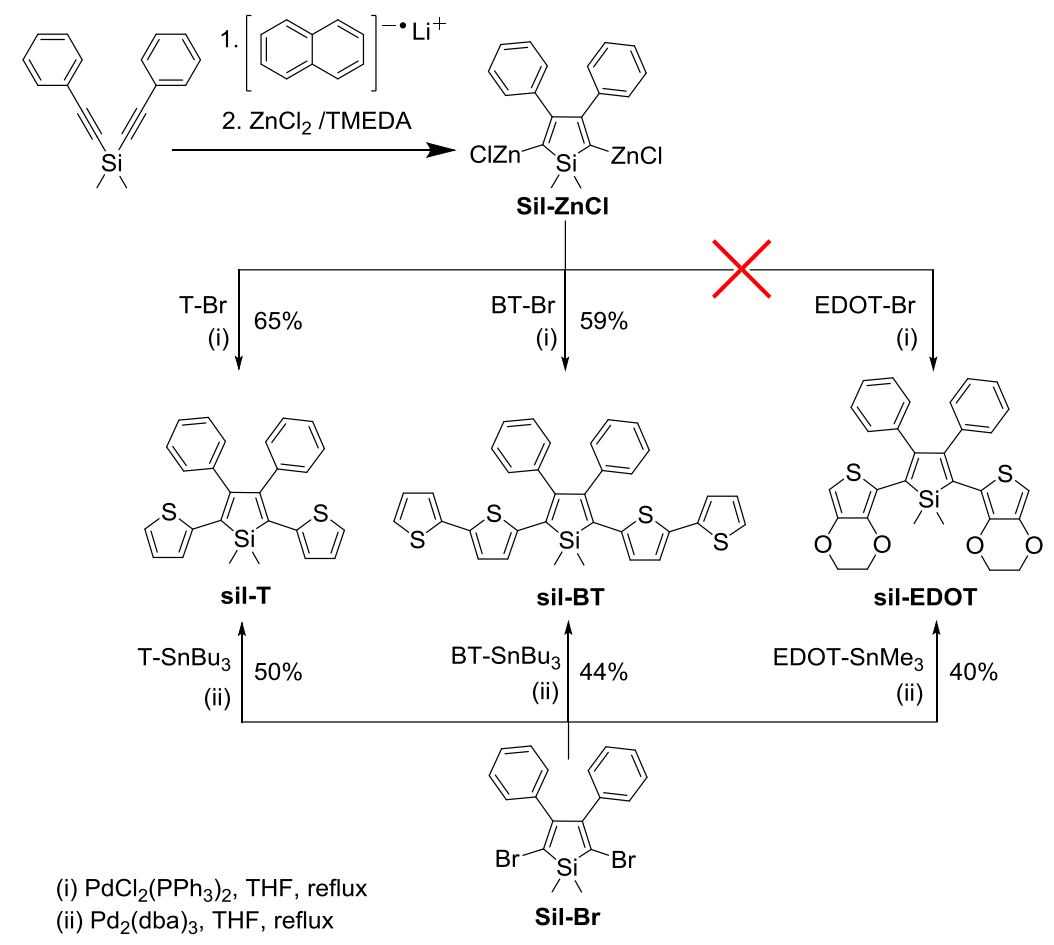

Scheme 1. Synthetic routes to silole derivatives.

The structures of sil-T, sil-BT and sil-EDOT were confirmed by multinuclear spectroscopy $\left({ }^{1} \mathrm{H},{ }^{13} \mathrm{C}\left\{{ }^{1} \mathrm{H}\right\}\right.$ and $\left.{ }^{29} \mathrm{Si}\left\{{ }^{1} \mathrm{H}\right\}\right)$ and mass spectrometry. The data obtained for sil-T and sil-BT are in good agreement with those previously published in the literature. ${ }^{58}$ For sil-EDOT, a multiplet at 4.20 ppm corresponding to the $\mathrm{CH}_{2} \mathrm{O}$ group of EDOT as well as a singlet assigned to the methyl group linked to the silicon at 0.62 ppm are noted in the ${ }^{1} \mathrm{H}$ NMR spectrum. A singlet at $10.8 \mathrm{ppm}$ is also observed in the ${ }^{29} \mathrm{Si}\left\{{ }^{1} \mathrm{H}\right\}$ NMR spectrum corresponding to the silicon atom of the silole core.

Single crystals were also obtained by slow evaporation of a solution of sil-EDOT in $\mathrm{CH}_{2} \mathrm{Cl}_{2} / n$-hexane. As observed for related siloles derivatives, ${ }^{74,76}$ the crystal structure of sil-EDOT (Fig. 1 and Fig. S24 in the Supporting Information) indicates that the 2,5thiophene rings have anti-coplanar arrangements to the central silole ring; the twisted angle between the two thiophene mean planes and the silole mean plane is only $1.96^{\circ}$. This coplanar arrangement is favoured by the presence of Si---O interactions since the intramolecular distance between the $\mathrm{Si}$ and $\mathrm{O}$ atoms of the silole and the EDOT rings of $3.04 \AA$ is markedly smaller than the sum of the van der 
Waals radii (3.62 Å). Strong Si---O interactions with short Si---O interatomic distance of $\sim 1.9-2.4 \AA$ are well known in the literature. ${ }^{77-80}$ The distance of $3.04 \AA$ observed in sil-EDOT suggests that the Si---O interactions are weak. This was confirmed by using ${ }^{29} \mathrm{Si} \mathrm{CP} / \mathrm{MAS}$ NMR spectroscopy by comparing the ${ }^{29} \mathrm{Si}$ chemical shifts of sil-EDOT and sil-T, where no Si---O interactions are present in the solid state. Indeed, the downfield ${ }^{29} \mathrm{Si}$ chemical shift of sil-EDOT compared to sil-T (10.2 ppm vs. $7.9 \mathrm{ppm}$ ) clearly indicates that this interaction is very weak (Fig. S23 in the Supporting Information). The rather strong $S-\pi$ interactions ${ }^{83}\left(d_{S-\pi}=3.24 \AA\right.$ ) between the thiophene moieties and the adjacent phenyl rings likely explains the quite uncommon nearly perpendicular arrangement of these groups in respect to the silole mean plane (torsion angle $=88.4^{\circ}$ ).

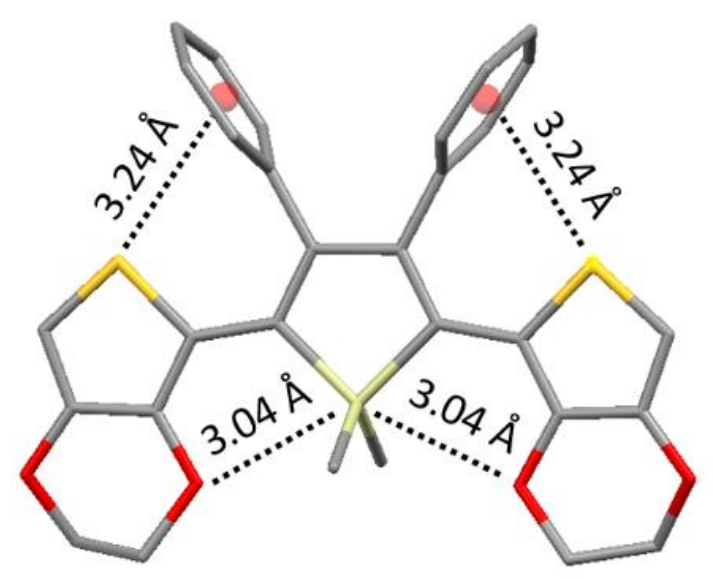

Figure 1. X-ray single-crystal structure of sil-EDOT showing the intramolecular Si-O and S- $\pi$ interactions.

Desilylation reactions of 3,4-diphenylsiloles are known to afford the corresponding DPBs in good yields. ${ }^{58,74}$ Following this strategy, DPBs were obtained in $60-87 \%$ yields by the treatment of 1,1-dimethylsiloles with ${ }^{n} \mathrm{Bu}_{4} \mathrm{NF}$ in THF under reflux (Scheme 2). The desilylation reaction was confirmed by ${ }^{1} \mathrm{H}$ NMR spectroscopy with the disappearance of the singlet around $0.7 \mathrm{ppm}$ assigned to the $\mathrm{Si}-\mathrm{CH}_{3}$ group and the appearance of a singlet at 6.3-6.4 ppm corresponding to the ethylenic protons. These compounds were also characterized by mass spectrometry. 

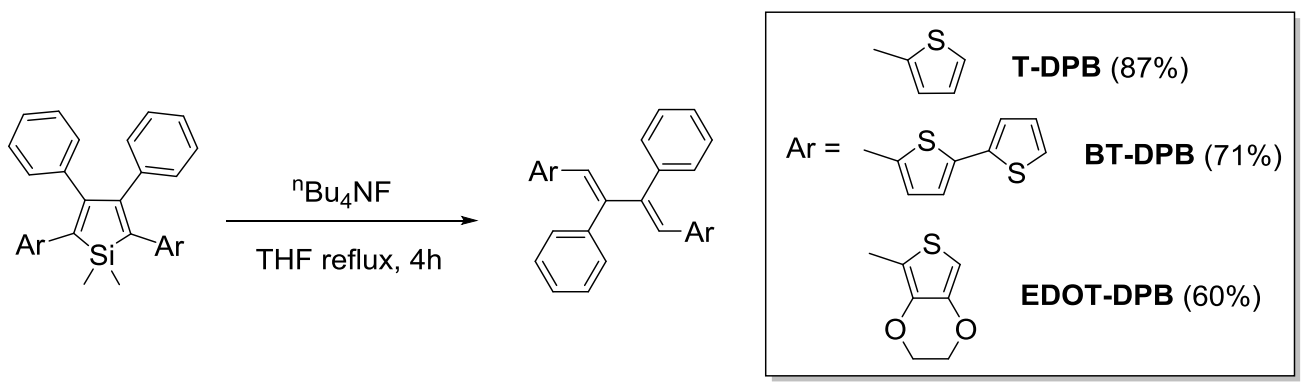

Scheme 2. Desilylation reaction for the synthesis of butadiene chromophores.

Unfortunately, we did not manage to obtain crystals from EDOT-DPB even using different solvents or mixtures. Only single crystals of T-DPB and BT-DPB were obtained from $\mathrm{CH}_{2} \mathrm{Cl}_{2} / n$-hexane mixtures allowing to gain insight into the packing and to determine the nature of the intermolecular interactions. The molecular structures of T-DPB and BT-DPB established by single crystal X-ray diffraction analyses are shown in Figure 2 and in Figures S25-S26 in the Supporting Information. The butadiene moiety adopts a coplanar transoïd orientation (Fig. $2 \mathrm{a}$ and $2 \mathrm{~d}$ ). The $\mathrm{C}=\mathrm{C}$ distances $(1.36 \AA)$ in the butadiene moiety are in good agreement with those previously found in the literature for other BT derivatives. ${ }^{58}$ The thiophene rings in TDPB and BT-DPB are almost in the same plane as the central butadiene moiety; the twisted angle between the two thiophene mean planes and the butadiene mean plane being of $3.83^{\circ}$ and $20.62^{\circ}$ for T-DPB and BT-DPB, respectively. The 2,3-diphenyl rings are twisted out of the plane of the diene angles with twisted angles of $77.97^{\circ}$ and $83.44^{\circ}$ for T-DPB and BT-DPB, respectively. Finally, as observed in the crystal structure of Sil-EDOT, significant $S-\pi$ interactions are found $\left(d_{S-\pi}=3.38 \AA\right.$ ) between the thiophene moieties and the adjacent phenyl rings.

T-DPB crystallizes as independent dimeric units (Fig. S25 in the Supporting Information). Presumably, as a result of the twisted conformations of the benzene rings attached with the butadiene backbone, no intermolecular $\pi-\pi$ stacking was observed in the crystal packing (Fig. $2 \mathrm{~b}$ and $2 \mathrm{c}$ ). Only short $\mathrm{C}-\mathrm{H} / \pi$ interactions $(2.9 \AA)$ are observed between two adjacent molecules ${ }^{81}$. In the case of BT-DPB, an organization into one-dimensional zigzag structure can be seen in the crystal packing due to the presence of $\mathrm{C}-\mathrm{H} / \pi(3.5 \AA)$ and $\mathrm{C}-\mathrm{H} / \mathrm{S}(3.5 \AA)$ interactions, rather than $\pi-\pi$ interactions (Fig. $2 \mathrm{e}$ and $2 \mathrm{f}$ ). The presence of these $\mathrm{C}-\mathrm{H} / \pi$ interactions for both 
molecules in the solid state indicates that the free-rotation of the phenyl rings is restricted in the solid, while it is not the case in solution. Since there is no close $\pi-\pi$ stacking interactions in these structures, the non-radiative deactivation of excitons is reduced. Consequently, T-DPB and BT-DPB possess all characteristic features for exhibiting AIE (AEE) properties. ${ }^{82-84}$

a/
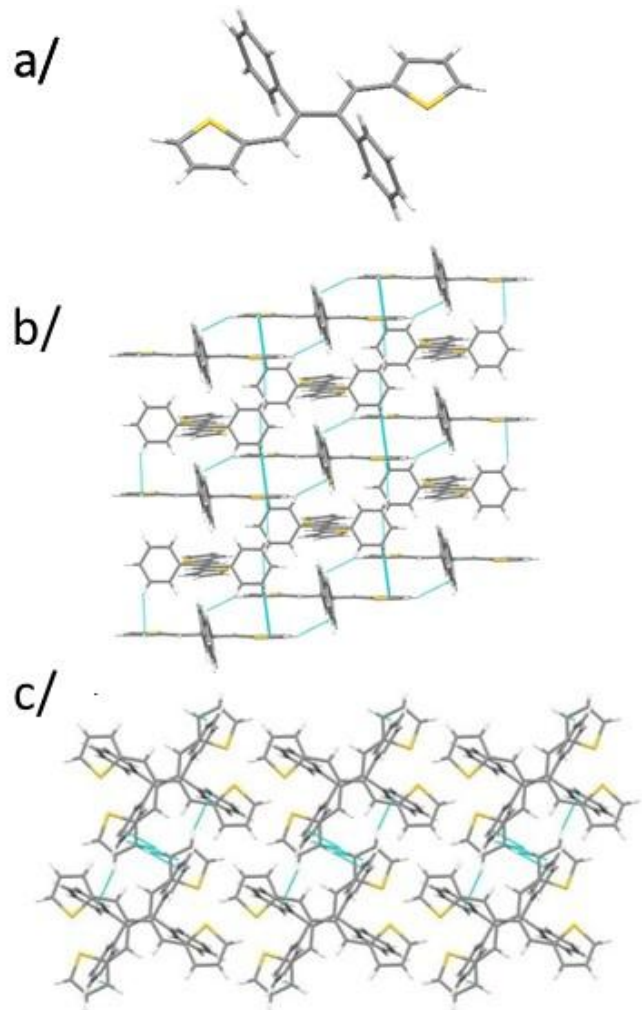

d/

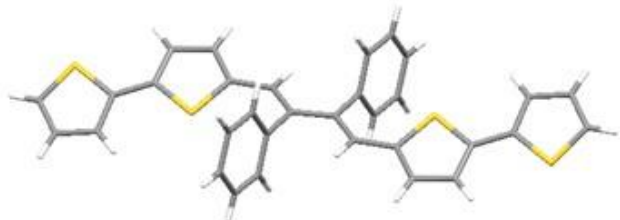

e/

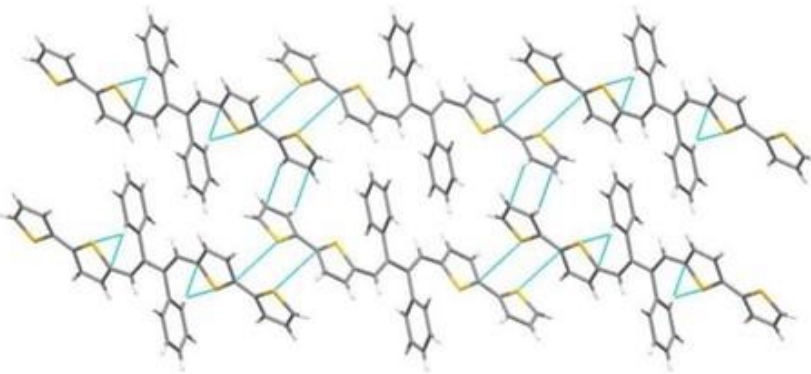

f/

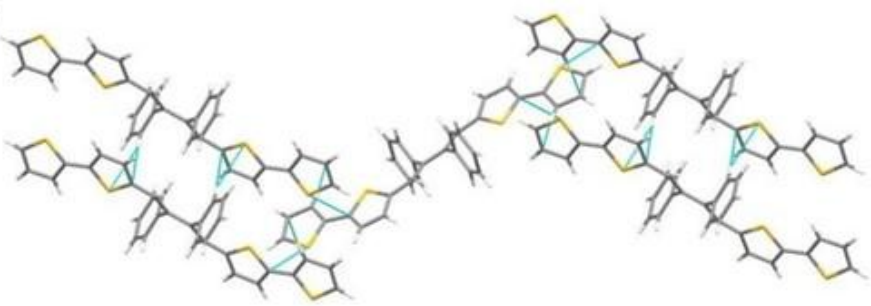

Figure 2. X-ray single-crystal structure of T-DPB (a) and BT-DPB (b) and views of crystal packing of TDPB (c-d) and BT-DPB (e-f).

\subsection{Optical properties}

The optical properties of DPBs were investigated by UV-Visible absorption and emission spectroscopy and the corresponding data are summarized in Table 1. All the DPBs exhibit absorption bands in the range between 340 and $460 \mathrm{~nm}$ with a more or less pronounced vibronic structure (Fig. 3). ${ }^{48,58}$ The introduction of a stronger donating thiophene group (EDOT) and a bisthienyl unit with a longer conjugation length results in an increase in the absorption maxima compared to T-DPB, following the order: $434 \mathrm{~nm}$ (BT-DPB) > $383 \mathrm{~nm}$ (EDOT-DPB) > $362 \mathrm{~nm}$ (T-DPB). The optical bandgaps (Eg) were also estimated from the onset 
wavelength of the UV-Vis absorption spectra, which are found in the order of T-DPB (3.11 eV) > EDOT-DPB (2.94 eV) > BT-DPB (2.56 eV) (Table 1).

Table 1. Optical characteristics of DPBs.

\begin{tabular}{c|ccc} 
& T-DPB & BT-DPB & EDOT-DPB \\
\hline$\lambda_{\text {abs }}(\mathrm{nm})$ & $346(27700)$ & $408(39700)$ & $365(36100)$ \\
$\left(\varepsilon\left({\left.\left.\mathrm{L} . \mathrm{mol}^{-1 .} \mathrm{cm}^{-1}\right)\right)}^{362(38800)}\right.\right.$ & $434(53700)$ & $383(56700)$ \\
$\lambda_{\text {em }}(\mathrm{nm})$ & $382(29500)$ & $460(39100)$ & $405(49500)$ \\
$\Phi_{\text {THF }}(\%)$ & 452 & 529 & 466 \\
$\Phi_{\text {agg }}(\%)^{\mathrm{a}}$ & 1 & 2 & 1 \\
Optical Eg $(\mathrm{eV})$ & 16 & 4 & 11 \\
Calculated $\mathrm{E}(\mathrm{eV})^{\mathrm{b}}$ & 3.11 & 2.56 & 2.94 \\
& 3.20 & 2.52 & 3.04
\end{tabular}

a aggregation with a $\mathrm{H}_{2} \mathrm{O}$ :THF (8:2) mixture; ${ }^{\text {b}}$ Energy band gap between HOMO-LUMO.

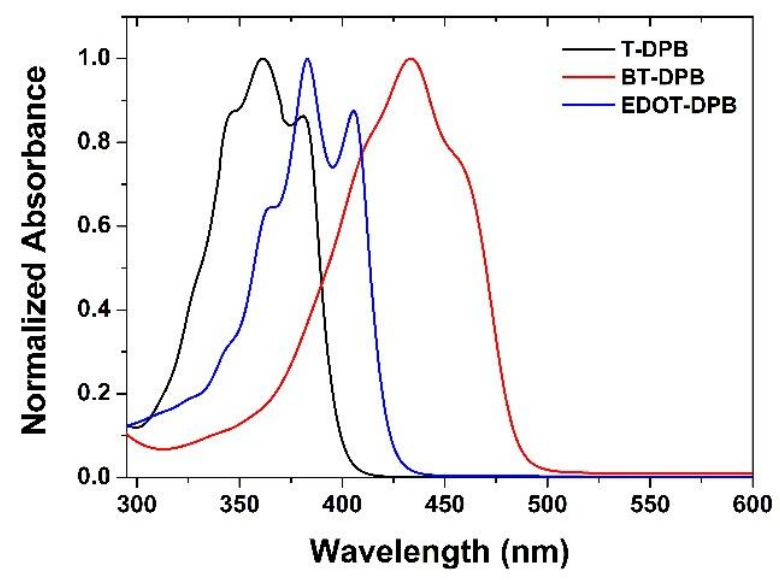

Figure 3. UV-Visible absorption spectra of DPBs in THF.

To support the optical behaviours of the DPBs derivatives theoretically, density functional theory (DFT) calculations (B3LYP/6-31+G* level) were carried out. The molecular structures of the different butadienes have been optimized starting from the crystal structures when available. The optimized structures and the shape of the HOMO and LUMO orbitals of T-DPB, BT-DPB and EDOT-DPB are depicted in Figure 4.

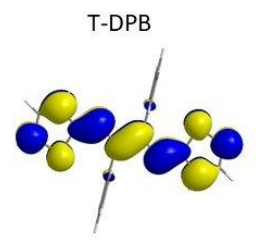

LUMO : $-2.01 \mathrm{eV}$

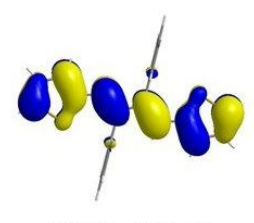

HOMO : $-5.24 \mathrm{eV}$
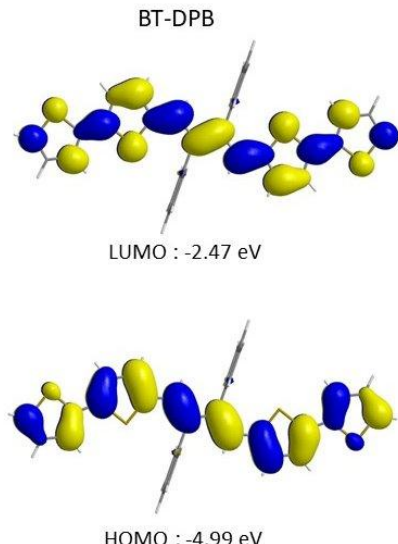

EDOT-DPB

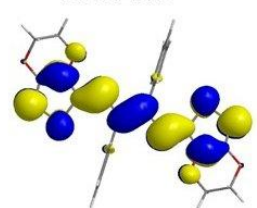

LUMO : $-1.86 \mathrm{eV}$

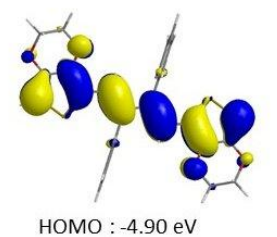


Figure 4. Energy and shape of the HOMO (bottom) and LUMO (top)orbitals of optimized structures of T-DPB, BT-DPB and EDOT-DPB, as calculated at the B3LYP/6-31+G* level.

The geometrical parameters extracted from the optimized structures are in very good accordance with those measured in the crystal structures (see ESI). Freed from crystal lattice constraints, the structures are much more planar. On the other hand, the calculations took rather well into account the S--- $\pi$ interaction found in the crystal structure of either T-DPB or BT-DPB ( $d_{s--\pi}$ calc $^{d}: 3.50 \AA$, crystal: $3.38 \AA$ ). As expected from the molecular geometry, the HOMO and LUMO orbitals are spread all over the $\pi$-conjugated skeleton. Because of their orthogonality a negligible electronic density is found on the central phenyl rings. Interestingly the calculated $E_{g}$ values are very close to those experimentally determined by UV-Visible absorption spectroscopy (see Table 1). This indicates that the conformation adopted by the butadienes in solution is well reproduced by the molecular optimization.

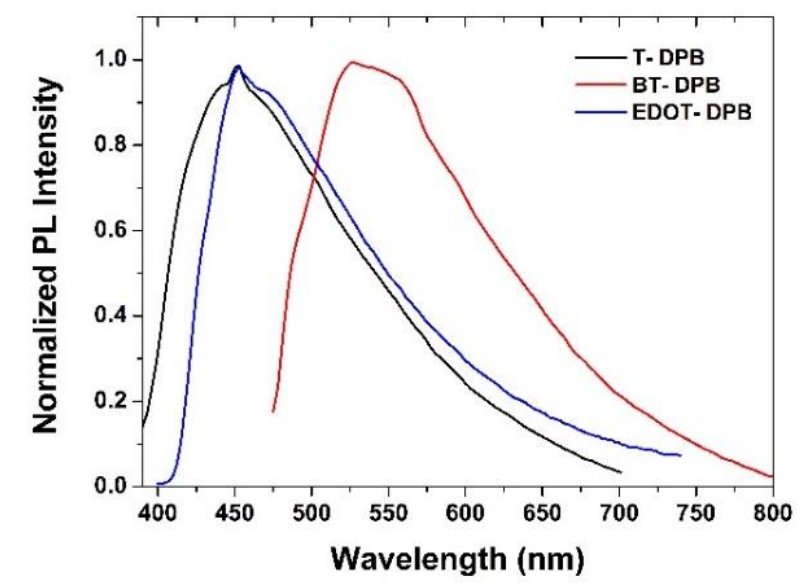

Figure 5. Emission spectra of T-DPB $\left(\lambda_{\text {exc }}=360 \mathrm{~nm}, 2.2 \times 10^{-6} \mathrm{M}\right.$, black), BT-DPB $\left(\lambda_{\text {exc }}=445 \mathrm{~nm}, 2.5 \mathrm{x}\right.$ $10^{-5} \mathrm{M}$, red) and EDOT-DPB ( $\lambda_{\text {exc }}=380 \mathrm{~nm}, 4 \times 10^{-5} \mathrm{M}$, blue) in THF.

Emission properties were then studied by recording fluorescence spectra in THF (Fig. 5) and their features are summarized in Table 1. The emission wavelengths of DPBs are in the range from blue (451 and $466 \mathrm{~nm}$ for T-DPB and EDOT-DPB, respectively) to green (529 $\mathrm{nm}$ for BT-DPB) depending on the substituent attached to the central butadiene core. T-DPB and BT-DPB, EDOT-DPB exhibit extremely low emission quantum yields (1-2\%), probably due to the free-rotation of the phenyl and thiophene rings in solution. 


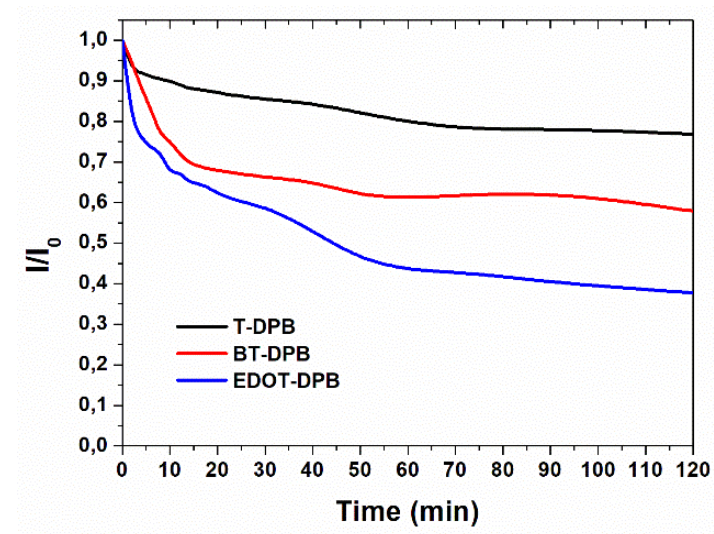

Figure 6. Changes of fluorescence intensity of DPBs (1 mM) in THF under the continuous irradiation from a 9 W UV lamp.

Before analysing the AIE/AEE properties of these butadienes, their photostability were investigated in THF $\left(10^{-3} \mathrm{M}\right)$ upon irradiation with a $9 \mathrm{~W}$ UV lamp at $365 \mathrm{~nm}$ for $120 \mathrm{~min}$. Figure 6 shows the photobleaching behaviour of T-DPB, BT-DPB and EDOTDPB, which was monitored by measuring the evolution of the fluorescence intensity at their emission maxima in steady-state fluorescence spectroscopy. As shown in Fig. 6, BT-DPB and EDOT-DPB are the less stable compounds with $40 \%$ and $60 \%$ decrease of their fluorescence intensity, respectively, while it is $20 \%$ for T-DPB. Regarding the relationship between electron density and the photobleaching rate, it is likely that the more the butadiene is electron rich, the faster photobleaching is, suggesting a photosensitizing oxidation mechanism. ${ }^{85,86}$

Compared to T-DPB and EDOT-DPB, BT-DPB exhibited a little emission in pure THF which remains almost constant up to $f_{w}=50 \%$. When $f_{w}$ reaches $60 \%$, PL continuously increases and a strong change in the absorption profile and a red-shifted emission is noticed from $f_{w}=70 \%$. Compared to intensity in pure THF, the emission only increases by $\sim 2.5$ fold at $\mathrm{f}_{\mathrm{w}}=90 \%$. According to these results, we can conclude that BT-DPB possess the unique characteristics of aggregation-enhanced emission (AEE). ${ }^{82,90}$ Such differences in the emission behaviour can be found in the molecular packing comparing T-DPB and BT-DPB crystal structures. As observed in Fig. 2, aromatic $\mathrm{C}-\mathrm{H} / \pi$ interactions were found in both T-DPB and BT-DPB crystal structures. 
This aromatic $\mathrm{C}-\mathrm{H} / \pi$ interactions enables stabilizing the twisted conformation of the DPBs. $^{82}$ Nevertheless, if we compare the distances of these aromatic $\mathrm{C}-\mathrm{H} / \pi$ interactions in T-DPB and BT-DPB crystal structures (2.9 ̊ for T-DPB vs. $3.5 \AA$ for BTDPB), the longer distance observed for BT-DPB suggests that the phenyl moieities can more freely rotate in the case of BT-DPB than T-DPB resulting in lower enhancement of the emission when moving to aggregates. ${ }^{82}$
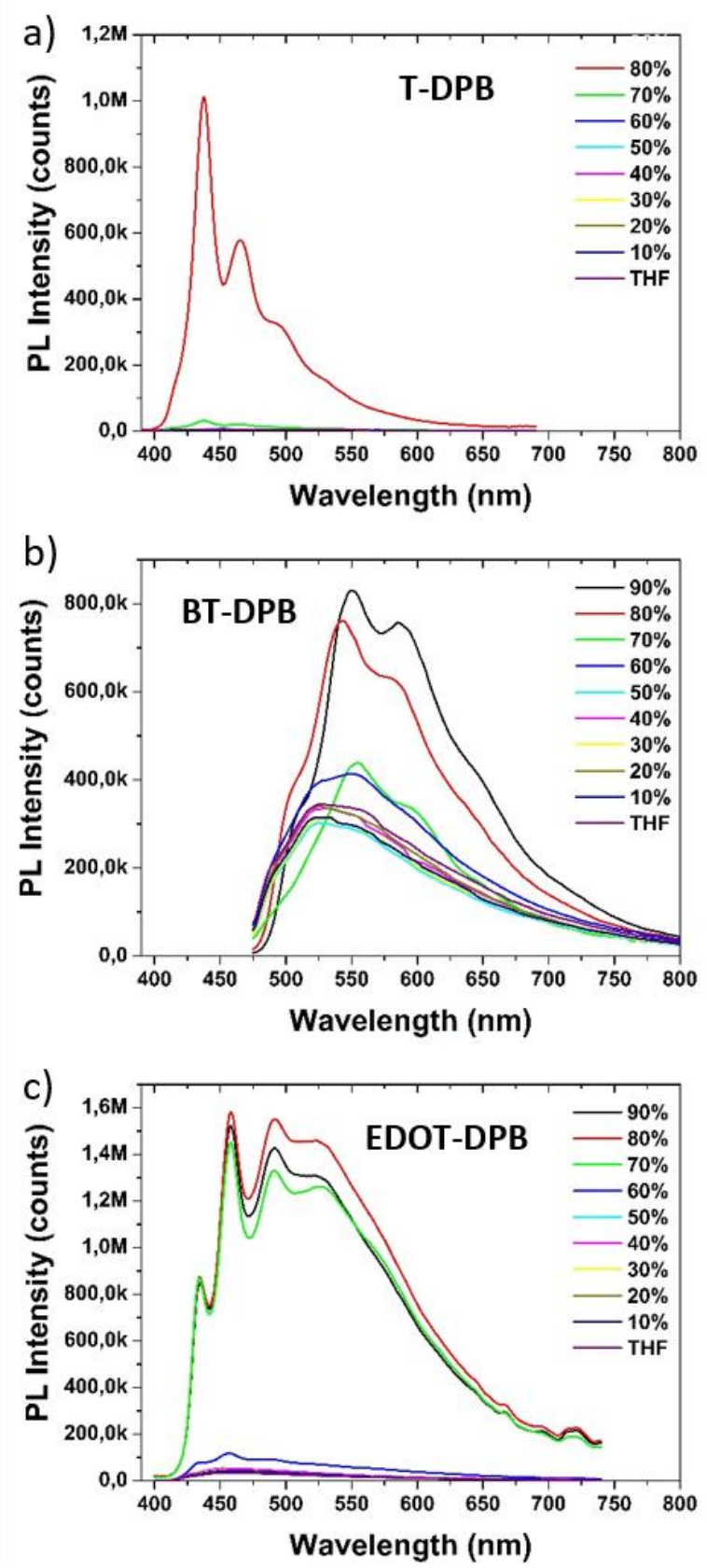

Figure 7. Emission spectra of a) T-DPB (concentration: $3 \times 10^{-5} \mathrm{M}, \lambda_{\text {exc }}=360 \mathrm{~nm}$ ), BT-DPB (concentration: $2.5 \times 10^{-5} \mathrm{M}, \lambda_{\text {exc }}=445 \mathrm{~nm}$ ) and c) EDOT-DPB (concentration: $4 \times 10^{-5} \mathrm{M}, \lambda_{\text {exc }}=380 \mathrm{~nm}$ ) in THF/water mixtures with different water fractions $\left(f_{w}\right)$. 
Electrochemical analysis of the three DPBs were performed by cyclic voltammetry (CV) in $\mathrm{CH}_{2} \mathrm{Cl}_{2}$ (see reduction in fig. 9a and oxidation in fig. 9b, all potentials are given vs. SCE). In reduction, the three compounds present an irreversible reduction wave with a maximum at $-2.36 \mathrm{~V}$ for T-DPB, $-2.08 \mathrm{~V}$ for BT-DPB and $-2.39 \mathrm{~V}$ for EDOT-DPB. From the onset potential of their reduction wave, it was possible to calculate the LUMO level of the three compounds at $-2.32 \mathrm{eV}$ for T-DPB, -2.59 eV for BT-DPB and $2.28 \mathrm{eV}$ for EDOT-DPB.
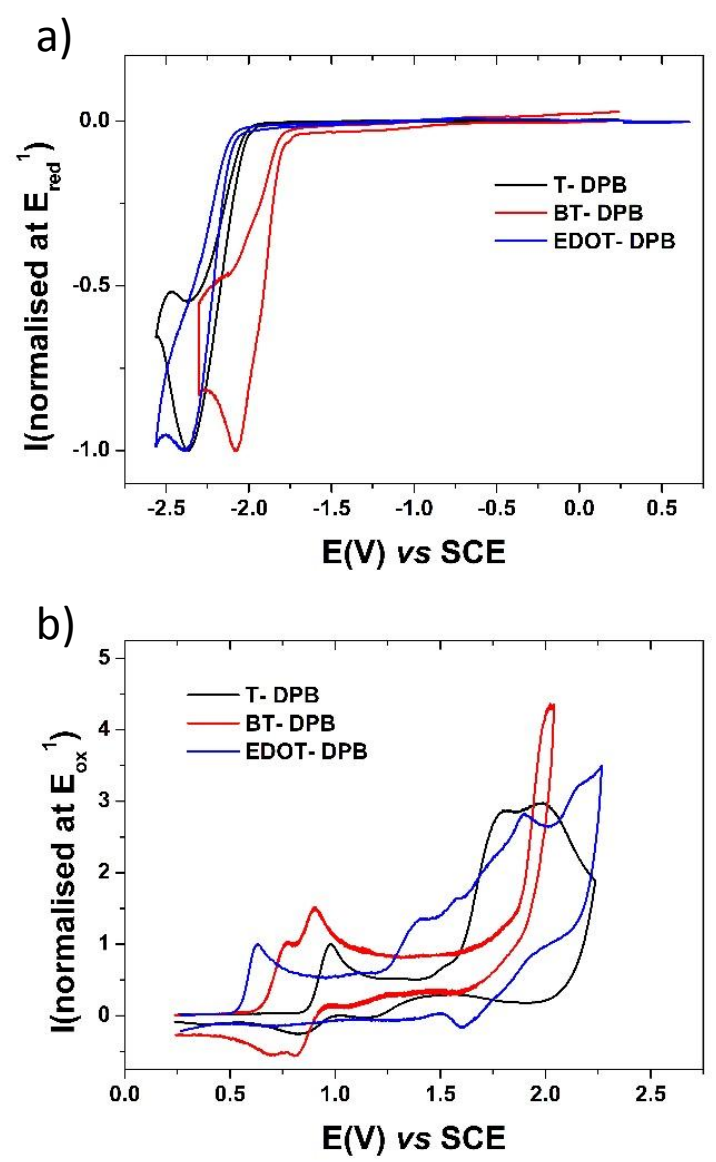

Figure 9. Normalized cyclic voltammograms of T-DPB, BT-DPB and EDOT-DPB, $\mathrm{CH}_{2} \mathrm{Cl}_{2}+\mathrm{Bu}_{4} \mathrm{NPF}_{6} 0.2$ $\mathrm{M}, 100 \mathrm{mV} . \mathrm{s}-1$, Pt disk working electrode. The CVs are normalized at the first respective a) reduction and b) oxidation waves.

In oxidation, the three compounds present successive oxidation processes between 0.25 and $2.25 \mathrm{~V}$. T-DPB is oxidized at the more positive values and present three waves with maxima at 0.98, 1.81 and $1.93 \mathrm{~V}$. Three waves are recorded for BT-DPB with maxima at 0.78, 
0.91 and $2.12 \mathrm{~V}$. Finally, EDOT-DPB is oxidized at the lowest first oxidation potential with five oxidation waves presenting maxima at $0.63,1.40,1.58,1.90$ and $2.17 \mathrm{~V}$. From the onset oxidation potential of their respective first oxidation, we calculated the HOMO level of the three compounds at $-5.28 \mathrm{eV}$ for T-DPB, $-5.06 \mathrm{eV}$ for BT-DPB and -4.95 eV for EDOT-DPB. The highest HOMO of EDOT-DPB compared to the one of BT-DPB and T-DPB is in accordance with the higher HOMO level of EDOT compared to the one of thienyl or dithienyl and indicate the extension of conjugation on the whole molecule for each compound. From their HOMO and LUMO values, we calculated the electrochemical bandgap Egelec of the three molecules $\left(E_{\text {gelec }}=\right.$ LUMO-HOMO) equal to $2.96 \mathrm{eV}$ for T-DPB, $2.47 \mathrm{eV}$ for BT-DPB and 2.67 $\mathrm{eV}$ for EDOT-DPB. The increase of $E_{\text {gelec }}$ from BT-DPB $(2.47 \mathrm{eV})$ to EDOT-DPB $(2.67 \mathrm{eV})$ and TDPB $(2.96 \mathrm{eV})$ is in accordance with the one obtained from optical data $(2.56,2.94$ and 3.11 $\mathrm{eV}$, see table 1) and from theoretical calculations (2.52, 3.04 and $3.20 \mathrm{eV}$, see table 1$)$.

Looking more deeply to the successive oxidation waves of each compounds shows the different electrochemical behaviour of the three molecules (see detailed CVs of each compounds in SI). For T-DPB, the first oxidation is irreversible (Fig. S33 in the Supporting Information) whatever the sweep-rate. When cycling at more positive values, i.e. higher than $1.75 \mathrm{~V}$ (the onset potential of the second oxidation wave with a maximum at $1.81 \mathrm{~V}$ ), an electrodeposition process is observed along recurrent scans by the appearance and the growth of a new reversible redox process at potential less anodic than the first oxidation of T-DPB) and by the covering of the electrode surface by an insoluble deposit (Fig. S34 in the Supporting Information). The presence of such deposit on the working electrode surface since the second oxidation of T-DPB renders difficult to fully detail the electrochemical process occurring at higher potential values (1.93 $\mathrm{V}$ ) because this third oxidation process may come from the oxidation of T-DPB as well as from the oxidation of its derived polymer. The electrodeposition process is more and more intense, increasing the anodic potential values from 1.75 to $2.0 \mathrm{~V}$. The insoluble deposits covering the electrode surface after such recurrent sweeps are electroactives both in oxidation and in reduction, the $\mathrm{n}$-doping process being however, largely less intense than the p-doping process (Fig. 10a). The p-doping process present a reversible wave with a maximum at $1.06 \mathrm{~V}$ and an onset oxidation value of $0.73 \mathrm{~V}$ (HOMO of poly(T-DPB): $-5.13 \mathrm{eV}$ ). In reduction, the onset potential is of $-0.81 \mathrm{eV}$ 
showing a LUMO of $-3.59 \mathrm{eV}$. The electrochemical bandgap $E_{\text {gelec }}$ of poly(T-DPB) is therefore of $1.54 \mathrm{eV}$.

For BT-DPB, the two first waves are reversible (see Fig. S35 in the Supporting Information) expressing a higher stability of the radical cation (BT-DPB ${ }^{+}$) and of the bis-radical cation or dication (BT-DPB ${ }^{2+}$ ) due to the extended conjugation of this compound compared to T-DPB.
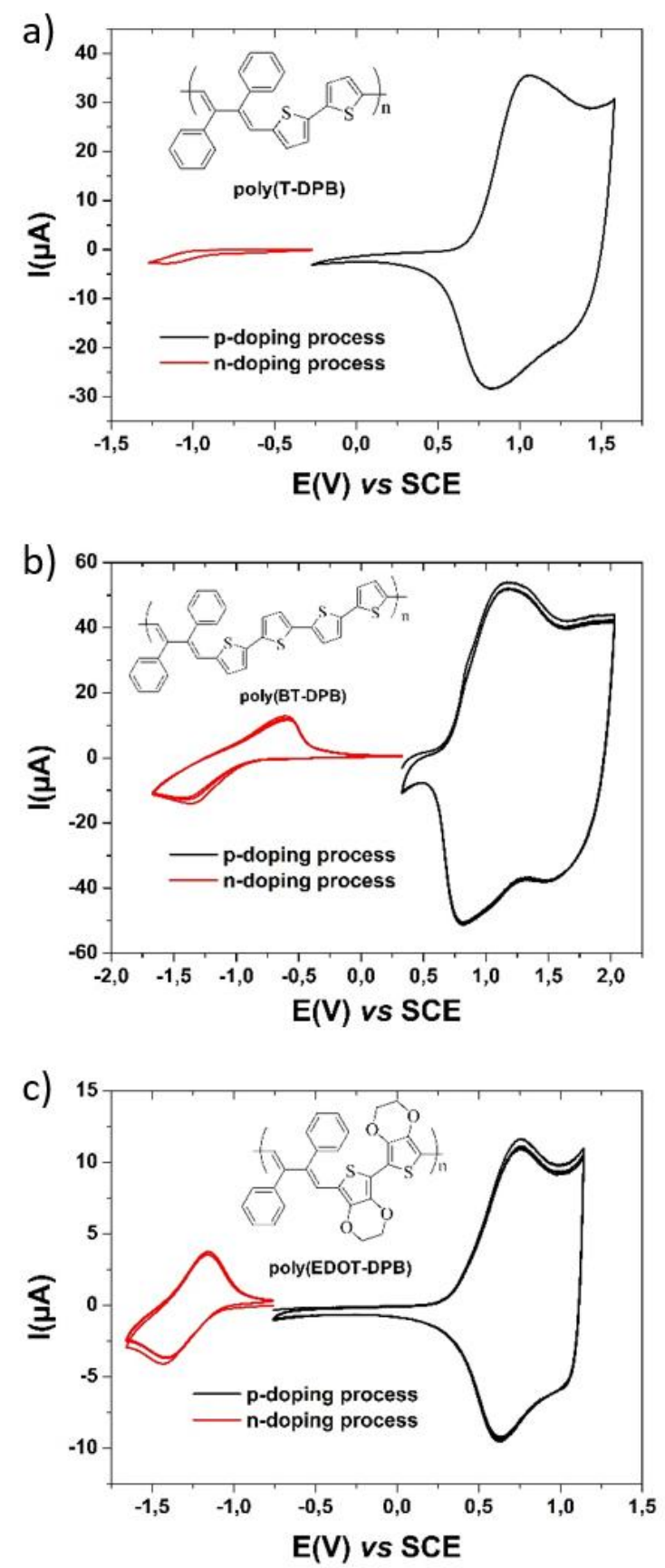

Figure 10. Cyclic voltammograms of three deposits obtained from the oxidation of T-DPB, BT-DPB and EDOT-DPB, $\mathrm{CH}_{2} \mathrm{Cl}_{2}+\mathrm{Bu}_{4} \mathrm{NPF}_{6} 0.2 \mathrm{M}, 100 \mathrm{mV} . \mathrm{s}^{-1}$, Pt disk working electrode. In black: the p-doping 
processes and in red: the $n$-doping processes. Poly(T-DPB) is obtained along 10 sweeps between 0.37 and $1.85 \mathrm{~V}$ in a T-DPB solution, Poly(BT-DPB) is obtained along 10 sweeps between 0.22 and $2.25 \mathrm{~V}$ in a BT-DPB solution, Poly(EDOT-DPB) is obtained along 10 sweeps between -0.7 and $1.99 \mathrm{~V}$ in a EDOT-DPB solution.

The electrodeposition process is observed when reaching potential more anodic than the third oxidation process (see Fig. S36 in the Supporting Information) as classically observed for other molecular systems. ${ }^{91,92}$ The deposits obtained from BT-DPB are also electroactives with $p$ - and $n$-doping processes, the latter being also less intense than the $p$ doping process but relatively more intense compared to the one of poly(T-DPB) (Fig. 10b). The onset potential of the p-doping process is recorded at $0.68 \mathrm{~V}$ and presents two successive oxidation waves with maxima at 1.18 and $1.87 \mathrm{~V}$. In reduction, the $\mathrm{n}$-doping process starts at $-0.94 \mathrm{~V}$ and presents a reversible $\mathrm{n}$-doping process with a maximum in reduction at $-1.39 \mathrm{~V}$. The $\mathrm{E}_{\text {gelec }}$ of poly(BT-DPB) is therefore calculated at $1.62 \mathrm{eV}$ slightly larger than the one of poly(T-DPB) $(1.54 \mathrm{eV})$.

Finally, for EDOT-DPB, the first oxidation process with the maximum at $0.63 \mathrm{~V}$ is irreversible (Fig. S37 in the Supporting Information). However, upon cycling up to $0.9 \mathrm{~V}$, an electrodeposition process is observed. This process being also more intense reaching anodic values increasing from 0.9 to $2.0 \mathrm{~V}$ (Fig. S38 in the Supporting Information). As a deposit is formed on the working electrode since the onset potential of the second oxidation wave (1.4 V), it is difficult to clearly ascribe the nature of the different oxidation processes occurring at more anodic potentials $(1.58,1.82,2.17 \mathrm{~V})$ as the different waves may be due to the oxidation of EDOT-DPB or of its derived polymer. The poly(EDOT-DPB) deposits also present $\mathrm{p}$ - and $\mathrm{n}$-doping processes (Fig. 10c) with the $\mathrm{n}$-doping process being less intense than the $\mathrm{p}$ doping one but more intense relatively to the $n$-doping processes of the previous polymers (see above $n$-doping processes of poly(T-DPB) and poly(BT-DPB)). Poly(EDOT-DPB) presents a p-doping process with an onset potential at $0.34 \mathrm{~V}$ and a maximum at $0.76 \mathrm{~V}$ and a $\mathrm{n}$ doping process with an onset potential at $-1.1 \mathrm{~V}$ and a maximum at $-1.4 \mathrm{~V}$.

As observed in Fig. 10, the n-doping processes of the three deposits are not similar both in term of onset potential values (LUMO) and of intensity of the electrochemical processes. Poly(T-DPB) possesses the lowest LUMO (-3.59 eV) followed by poly(BT-DPB) ($3.46 \mathrm{eV})$ and the poly(EDOT-DPB) $(-3.30 \mathrm{eV})$. The LUMO levels have decreased from the 
monomer to the polymer of around $1 \mathrm{eV}(1.27 \mathrm{eV}$ for T-DPB, $0.87 \mathrm{eV}$ for BT-DPB and $1.02 \mathrm{eV}$ for EDOT-DPB). In term of intensity, the less intense n-doping process (in comparison with the $p$-doped process) is observed for poly(T-DPB) whereas the $n$-doping is more intense for poly(BT-DPB) and poly(EDOT-DPB). This variation in intensity may be related to the difficulty of the rather bulky tetrabutylammonium cation to diffuse in the different polymer bulks to insure electroneutrality of the $n$-doped polymer. This may be in relation with the different structure in term of density or porosity of the three polymers. It should be pointed out that such difference in intensity between the $\mathrm{p}$ - and $\mathrm{n}$-doping processes has been previously observed for other deposits with $n$-doping either less intense ${ }^{93,94}$ or more intense ${ }^{95,96}$ than the p-doping process and may be due to the nature of the polymers but also, to the composition of the electrolytic medium in which the polymer is studied. The difference between the HOMO $(-4.74 \mathrm{eV})$ and $\operatorname{LUMO}(-3.30 \mathrm{eV})$ levels, calculated from the onset potential values, indicates that poly(EDOT-DPB) presents a bandgap of $1.44 \mathrm{eV}$, smallest compared to poly(T-DPB): $1.54 \mathrm{eV}$ and poly(BT-DPB): $1.62 \mathrm{eV}$.

What is the electropolymerization process? Due to the presence of thienyl, bithienyl or EDOT units at the external position of the diphenylbuta-1,3-diene core, the coupling between two monomer units should involve these thienyl, bithienyl or EDOT units. Such coupling classically occurs between the carbon atoms in $\alpha$ position of the sulfur of the thienyl $\left.\right|^{97,98}$ or the EDOT groups. ${ }^{99-103}$ Depending on the studied molecule, on the potential reached during the electrodeposition process and on the number of scans, the insoluble deposit possesses its own electrochemical behaviour. A possible structure of the polymers is proposed in insets of Fig. 10.

Electrodepositions were also performed along oxidation at fixed potentials on classical platinum disk and also on transparent glasses coated by ITO (indium-tin oxide) in order to record the absorption spectra of the deposits under their neutral (undoped) or pdoped state. Although appealing to go more in-depth in the knowledge of the electronic properties of the deposits, these studies are difficult to be completed. In fact, if the deposit is too thick, it is difficult to be totally reduced and on the other hand, too thin deposits may be more soluble and thus, may be dissolved when rinsing the modified ITO electrode between the electrochemical cell and the UV-visible spectrophotometer tank or may also be scratched from the ITO surface upon rinsing. 
The UV-Visible absorption spectra of the three deposits under their neutral or $\mathrm{p}$ doped states are presented in Figure 11. In Figure 11a, the p-doped poly(T-DPB) exhibits a large absorption band centered around $400 \mathrm{~nm}$ and a conduction band centered at $1050 \mathrm{~nm}$ (black line). Under its undoped neutral state (red line), the polymer absorbs between 300 and $700 \mathrm{~nm}$ with an onset absorption wavelength around $630 \mathrm{~nm}$ which expresses in a 1.96 $\mathrm{eV}$ optical bandgap contracted of $1 \mathrm{eV}$ compared to the optical bandgap of its monomer TDPB $(2.96 \mathrm{eV})$. This bandgap contraction shows a significant extension of conjugation in the deposit. The conduction band centered at $1050 \mathrm{~nm}$ indicates a conduction band of less than $1 \mathrm{eV}$ (ca: $0.88 \mathrm{eV}$ by extrapolation of the onset wavelength of the conduction band (1404 $\mathrm{nm})$.

a)
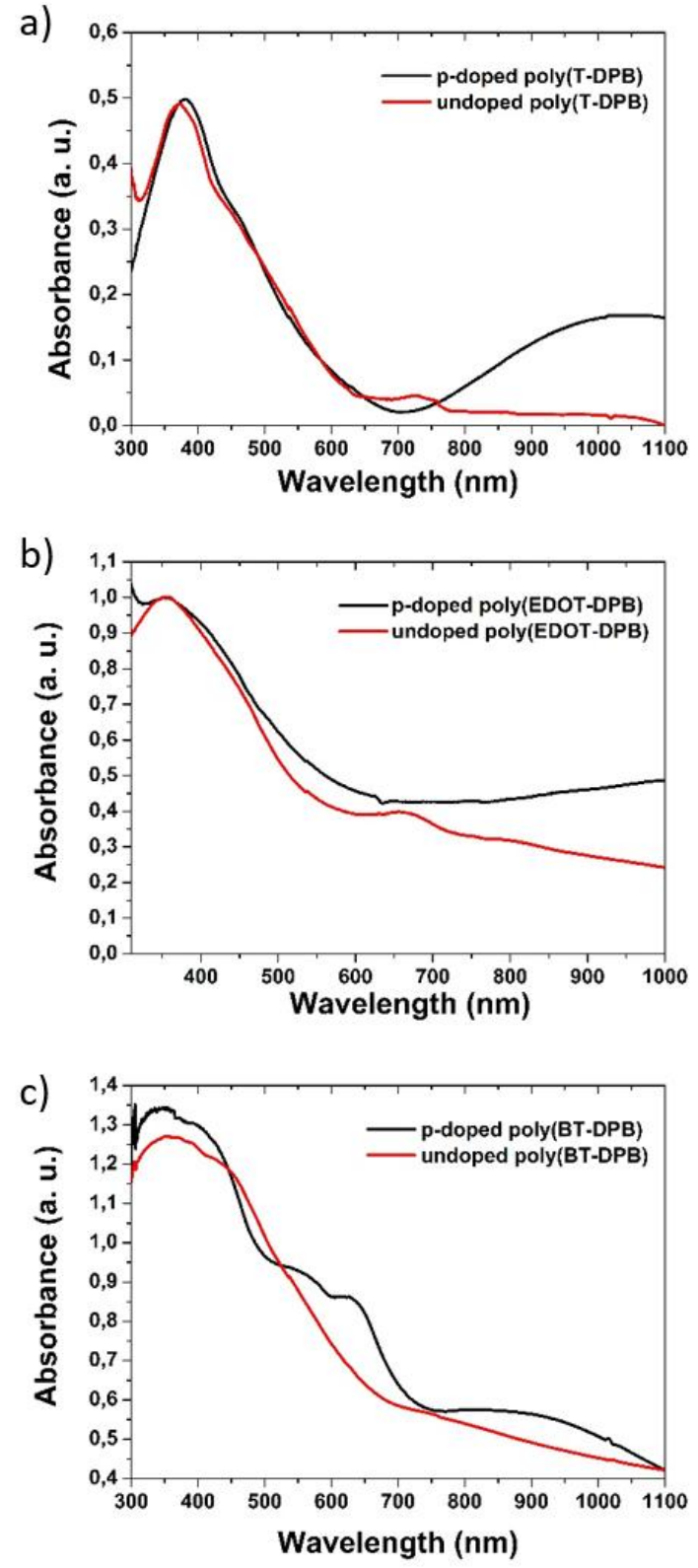
Figure 11. Absorption spectra of the polymers obtained on ITO surface by anodic oxidation of T-DPB, BT-DPB and EDOT-DPB. The spectra are recorded with the neutral (undoped) or p-doped states of the deposits.

Poly(BT-TPB) under its $p$-doped form present four absorption bands centered around 400, 600 and $900 \mathrm{~nm}$ (Fig. 11b, red line). When undoped, only the large absorption band around $400 \mathrm{~nm}$ remains with an onset absorption wavelength of ca. $640 \mathrm{~nm}$ which corresponds to an optical bandgap of ca $1.9 \mathrm{eV}$ and thus, to a contraction of the bandgap of $0.57 \mathrm{eV}$ compared to its monomer BT-DPB (2.47 eV). Therefore, poly(T-DPB) and poly(BTDPB) exhibit similar absorption spectra under their neutral states. However, the conduction band of poly(BT-DPB) is centered at ca $840 \mathrm{~nm}$ with an onset of $1090 \mathrm{~nm}$ showing a larger conduction band $(1.13 \mathrm{eV})$ compared to the one of $\mathrm{p}$-doped poly(T-DPB) $(0.88 \mathrm{eV})$ and indicating a higher conductivity in $p$-doped poly(T-DPB) than in $p$-doped poly(BT-DPB).

Finally, the deposits obtained by oxidation of EDOT-DPB are easier to prepare due to an efficient electropolymerization process attributable to efficient EDOT-EDOT coupling, but the deposits are the most difficult to reduce due to their thicknesses. Under their neutral form (recorded for a thin deposit), the optical bandgap of poly(EDOT-DPB) is $1.46 \mathrm{eV}$ ( $\lambda$ onset ca $850 \mathrm{~nm}$ ). The polymer optical bandgap is therefore $1.45 \mathrm{eV}$ more contracted than the one of EDOT-DPB (2.91 eV) indicating an important extension of conjugation in the polymer. Compared to the poly(T-DPB) and poly(BT-DPB), poly(EDOT-DPB) optical bandgap is also contracted of 0.5 and $0.44 \mathrm{eV}$, respectively. Finally, the absorption spectrum of poly(EDOTDPB) under its $p$-doped state presents a maximum value at wavelength higher than $1000 \mathrm{~nm}$ leading by extrapolation to a conduction band similar to the one of poly(T-DPB) and therefore, smaller than the one of poly(BT-DPB) also indicating a high conductivity for the deposit under its $\mathrm{p}$-doped form.

In conclusion, these UV-visible absorption studies follow similar tendency than the electrochemical studies (see above) which showed that polymers derived from T-DPB and BT-DPB possess similar bandgaps ( $E_{\text {gelec }}$ of 1.54 and $1.62 \mathrm{eV}$, respectively and $E_{\text {gopt }}$ of 1.96 and $1.90 \mathrm{eV}$, respectively) but larger than the bandgap of the deposit derived from EDOTDPB ( $E_{\text {gelec }}$ of $1.44 \mathrm{eV}$ and $E_{\text {gopt }}$ of $1.45 \mathrm{eV}$ ) which may be considered as a low bandgap polymer. 


\section{Experimental section}

\subsection{Materials}

All reactions were performed under an argon atmosphere. Dry THF was obtained by using a solvent purification system PuresolveMD5 from Inert $^{\circledR}$. Anhydrous $\mathrm{N}, \mathrm{N}-$ Dimethylformamide (DMF) (99.8\%) was purchased from Sigma-Aldrich. 2,5-dibromo-1,1dimethyl-3,4-diphenylsilole ( $\mathrm{TCl},<98 \%), 2$-(tributylstannyl)thiophene ( $\left.\mathrm{T}-\mathrm{SnBu}_{3}\right)$ (Aldrich, 97\%), n-tetrabutylammonium fluoride (Sigma-Aldrich, $1 \mathrm{M}$ in THF) and Tris(dibenzylideneacetone)palladium(0)-chloroform adduct $\left(\mathrm{Pd}_{2}(\mathrm{dba})_{3}\right.$, Aldrich) were used as received. The Tamao synthetic procedure allowing to obtain 1,1-dimethyl-3,4-diphenyl-2,5dithienylsilole (Sil-T) and 1,1-dimethyl-3,4-diphenyl-2,5-bis(5-(2,2'-bithienyl))silole (Sil-BT) is published elsewhere. $^{58}$ 5-tributylstannyl-2,2'-bithiophene (BT-SnBu $)$, 2-(trimethylstannyl)3,4-ethylenedioxythiophene (EDOT-SnMe $\mathbf{M}_{3}$ ) was prepared according to literature procedures. $^{104,105}$

\subsection{Techniques}

The NMR spectra were recorded on a BRUKER Avance III - $500 \mathrm{MHz}$ or a BRUKER Avance III $-600 \mathrm{MHz}$. The chemical shifts were referred to the solvent peak, $\delta=5.32 \mathrm{ppm}$ and $\delta=$ $54.0 \mathrm{ppm}$ for $\mathrm{CD}_{2} \mathrm{Cl}_{2}, \delta=7.26 \mathrm{ppm}$ and $\delta=77.16 \mathrm{ppm}$ for $\mathrm{CDCl} 3$ or $\delta=2.50 \mathrm{ppm}$ and $\delta=$ 39.52 ppm for dmso-d $d^{6}$ for ${ }^{1} \mathrm{H}$ and ${ }^{13} \mathrm{C}\left\{{ }^{1} \mathrm{H}\right\}$ NMR spectra, respectively. Solid-state ${ }^{29} \mathrm{Si} \mathrm{CP} / \mathrm{MAS}$ NMR spectra were recorded on a Varian VNMRS $300 \mathrm{MHz}$ spectrometer at resonance frequency of $59.60 \mathrm{MHz}$ for ${ }^{29} \mathrm{Si}$ using the cross-polarization (CP), magic-angle spinning (MAS), and a high-power ${ }^{1} \mathrm{H}$ decoupling. The powder samples were placed in a pencil-type zirconia rotor of $3.2 \mathrm{~mm}$ diameter. The spectra were obtained at a spinning rate of $6 \mathrm{kHz}$ (4 $\mu \mathrm{s} 90^{\circ}$ pulses), a 5-ms CP pulse, and a recycle delay of $20 \mathrm{~s}$. The Si signal of tetramethylsilane (TMS) at $0 \mathrm{ppm}$ was used as the reference of ${ }^{29} \mathrm{Si}$ chemical shift. The mass spectra were recorded on a Synapt G2-S (Waters) with an ASAP ionization source and a QTOF analyser. The UV-Visible absorption spectra were recorded at $25^{\circ} \mathrm{C}$ on a JASCO V-650 spectrophotometer in $10 \mathrm{~mm}$ quartz cells (Hellma). The extinction coefficient were determined by preparing solutions of butadiene derivatives at different concentration in THF. The concentration range was chosen to remain in the linear range of the Beer-Lambert relationship (A ca. 0.2-0.8). The onset wavelength of the absorption spectra was determined by the intersection of the straight line fitted to the right hand side of the maximum peak 
(382 $\mathrm{nm}$ for T-DPB, $405 \mathrm{~nm}$ for EDOT-DPB and $460 \mathrm{~nm}$ for BT-DPB, respectively) with the baseline of the absorption spectra ${ }^{106,107}$ (Figure S27 in the Supporting Information). The emission spectra were recorded at $25^{\circ} \mathrm{C}$ on a fluorescence spectrophotometer (FS920, Edinburgh Instrument), equipped with a calibrated photomultiplier in a Peltier (air cooled) housing (R928P, Hamamatsu), with a 450W continuous Xenon arc lamp as the excitation source for steady-state photoluminescence measurement using a $10 \mathrm{~mm}$ quartz cells (Hellma) with excitation path length. All electrochemical experiments were performed under an argon atmosphere, using a Pt disk electrode (diameter1 $\mathrm{mm}$ ), the counter electrode was a vitreous carbon rod and the reference electrode was a silver wire in a $0.1 \mathrm{M} \mathrm{AgNO}_{3}$ solution in $\mathrm{CH}_{3} \mathrm{CN}$. Ferrocene was added to the electrolyte solution at the end of a series of experiments. The ferrocene/ferrocenium $\left(\mathrm{Fc}_{\mathrm{Cc}}{ }^{+}\right)$couple served as the internal standard. The three electrode cell was connected to a PAR Model 273 potentiostat/galvanostat (PAR, $E G \& G, U S A)$ monitored with the ECHEM Software. Activated $\mathrm{Al}_{2} \mathrm{O}_{3}$ was added to the electrolytic solution to remove excess moisture. All potentials are referred to the SCE electrode that was calibrated at $-0.405 \mathrm{~V}$ vs. the $\mathrm{Fc} / \mathrm{Fc}^{+}$system.

\subsection{Synthetic procedures}

General procedure for the preparation of silole derivatives by Stille crooscoupling.

2,5-dibromo-1,1-dimethyl-3,4-diphenylsilole (200 $\mathrm{mg}, 0.5 \mathrm{mmol}, 1 \mathrm{eq})$, tris(dibenzylideneacetone)palladium (0)-chloroform adduct $(24.8 \mathrm{mg}, 25 \mu \mathrm{mol}, 5$ mol\%), triphenylphosphine (12.5 mg, $50 \mu \mathrm{mol}, 10 \mathrm{~mol} \%)$ were dissolved in anhydrous THF into a two-neck round-bottom flask under argon atmosphere. The stannyl derivative was added into the solution, then the mixture was stirred and heated under reflux for $15 \mathrm{~h}$. The mixture was concentrated and purified by flash chromatography using cyclohexane / DCM as eluent (100/0 - 90/10).

Sil-T: yellow powder. Yield $106 \mathrm{mg}$ (0.25 mmol, 50\%). ${ }^{1} \mathrm{H} \mathrm{NMR}\left(500 \mathrm{MHz}, \mathrm{CD}_{2} \mathrm{Cl}_{2}, \delta\right)$ : 7.22-7.17 (m, 6H), 7.04-7.00 (m, 6H), 6.92-6.87 (m, 4H), 0.69 (s, 6H, CH $\mathrm{CH}_{3} \mathrm{ppm} .{ }^{13} \mathrm{C}\left\{{ }^{1} \mathrm{H}\right\}$ NMR (125 MHz, $\left.\mathrm{CD}_{2} \mathrm{Cl}_{2}, \delta\right):$ 153.0, 143.2, 139.8, 132.2, 130.1, 129.0, 127.6, 127.5, 126.7, 126.2, -1.8 (Si-CH3) ppm. ${ }^{29} \mathrm{Si}\left\{{ }^{1} \mathrm{H}\right\} \mathrm{NMR}\left(99.5 \mathrm{MHz}, \mathrm{CD}_{2} \mathrm{Cl}_{2}\right.$, $)$ ): 9.5 ppm. HR-MS $\left(\text { ASAP }^{+} \text {) m/z calc. for } \mathrm{C}_{26} \mathrm{H}_{23} \mathrm{~S}_{2} \mathrm{Si}^{+} \text {[Sil-T }+\mathrm{H}\right]^{+}$427.1010; found, 427.1014.

Sil-BT: red powder. Yield $128 \mathrm{mg}(0.22 \mathrm{mmol}, 44 \%) .{ }^{1} \mathrm{H} \mathrm{NMR}\left(500 \mathrm{MHz}, \mathrm{CD}_{2} \mathrm{Cl}_{2}, \delta\right)$ : 7.26-7.20 (m, 6H), 7.17-7.16 $(\mathrm{m}, 2 \mathrm{H}), 7.06-7.03(\mathrm{~m}, 4 \mathrm{H}), 6.97\left(\mathrm{~d},{ }^{3} \mathrm{~J}_{\mathrm{H}-\mathrm{H}}=3.9 \mathrm{~Hz}, 2 \mathrm{H}\right)$, 
6.95-6.91 (m, 4H), $6.82\left(\mathrm{~d},{ }^{3} \mathrm{~J}_{\mathrm{H}-\mathrm{H}}=3.9 \mathrm{~Hz}, 2 \mathrm{H}\right), 0.62\left(\mathrm{~s}, 6 \mathrm{H}, \mathrm{CH}_{3}\right)$ ppm. ${ }^{13} \mathrm{C}\left\{{ }^{1} \mathrm{H}\right\} \mathrm{NMR}(125$

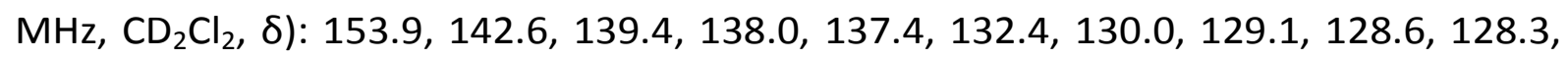
127.9, 127.9, 124.8, 123.8, 123.5, -1.6 $\left(\mathrm{Si}_{-} \mathrm{CH}_{3}\right)$ ppm. ${ }^{29} \mathrm{Si}\left\{{ }^{1} \mathrm{H}\right\}$ NMR $\left(99.5 \mathrm{MHz}, \mathrm{CD}_{2} \mathrm{Cl}_{2}\right.$,

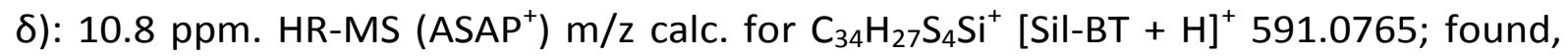
591.0766.

Sil-EDOT: orange-yellow powder. Yield: $108 \mathrm{mg}(0.2 \mathrm{mmol}, 40 \%) .{ }^{1} \mathrm{H}$ NMR (500 $\left.\mathrm{MHz}, \mathrm{CD}_{2} \mathrm{Cl}_{2}, \delta\right):$ 7.16-7.12 (m, 6H), 6.97-6.95 (m, 4H), $5.98(\mathrm{~s}, 2 \mathrm{H}), 4.22-4.18(\mathrm{~m}, 8 \mathrm{H}$, $\mathrm{CH}_{2}$ ), 0.62 (s, 6H, CH$)_{3}$ ppm. ${ }^{13} \mathrm{C}\left\{{ }^{1} \mathrm{H}\right\}$ NMR (125 MHz, $\left.\mathrm{CD}_{2} \mathrm{Cl}_{2}, \delta\right): 150.9,141.3,140.3$, 140.0, 130.8, 129.6, 128.7, 127.5, 119.9, 100.1, 65.1, 64.0, -3.3 (Si-CH3) ppm. ${ }^{29} \mathrm{Si}\left\{{ }^{1} \mathrm{H}\right\}$

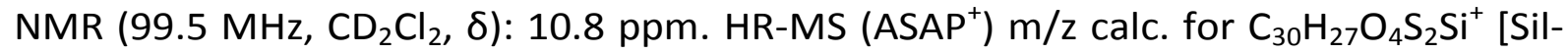
EDOT $+\mathrm{H}]^{+}$542.1042; found, 542.1050.

General procedure for the preparation of DPB derivatives. Silole $(0.55 \mathrm{mmol})$ was dissolved in THF $(20 \mathrm{~mL})$ into a two-neck round-bottom flask. A solution of $n$ tetrabutylammonium fluoride $(5.5 \mathrm{~mL}, 1 \mathrm{M}$ in THF, $5.5 \mathrm{mmol}, 10$ eq.) was added. Then, the mixture was stirred and heated under reflux for $4 \mathrm{~h}$. After cooling at room temperature, the mixture was quenched with water $(100 \mathrm{~mL})$. The reaction mixture was extracted with $\mathrm{CH}_{2} \mathrm{Cl}_{2}(2 \times 50 \mathrm{~mL})$. Then, the combined organic phases were dried with $\mathrm{MgSO}_{4}$ and evaporated under vacuum. The residue was recrystallized from $\mathrm{CH}_{2} \mathrm{Cl}_{2} / n$-hexane mixture.

T-DPB: pale yellow crystals. Yield: $178 \mathrm{mg}$ (0.48 mmol, 87\%). ${ }^{1} \mathrm{H} \mathrm{NMR}(600 \mathrm{MHz}$, $\left.\mathrm{CDCl}_{3}, \delta\right): 7.59-7.50(\mathrm{~m}, 6 \mathrm{H}), 7.39-7.33(\mathrm{~m}, 4 \mathrm{H}), 6.98\left(\mathrm{~d}, 2 \mathrm{H}^{3} \mathrm{~J}_{\mathrm{H}-\mathrm{H}}=5.1 \mathrm{~Hz}\right), 6.77(\mathrm{dd}$, $\left.2 \mathrm{H},{ }^{3} \mathrm{~J}_{\mathrm{H}-\mathrm{H}}=5.1,3.7 \mathrm{~Hz}\right), 6.62\left(\mathrm{dd}, 2 \mathrm{H},{ }^{3} \mathrm{~J}_{\mathrm{H}-\mathrm{H}}=3.7 \mathrm{~Hz}, 1 \mathrm{~Hz}\right), 6.36(\mathrm{~s}, 2 \mathrm{H},=\mathrm{CH}) \mathrm{ppm} ;{ }^{13} \mathrm{C}\left\{{ }^{1} \mathrm{H}\right\}$ NMR (150 MHz, $\left.\mathrm{CDCl}_{3}, \delta\right): 142.8,141.6,138.5,130.7,129.7,129.2,128.3,127.0$, 126.2, 125.0 ppm. HR-MS (ASAP ${ }^{+}$) m/z: calc for $\mathrm{C}_{24} \mathrm{H}_{19} \mathrm{~S}_{2}{ }^{+}$[T-DPB+ H] ${ }^{+}$370.0850; found, 370.0853; UV-Vis (THF) $\lambda \max \left(\varepsilon\right.$, L. mol $\left.^{-1} \cdot \mathrm{cm}^{-1}\right)=346$ (27 700), 362 (38 800), 382 (29 500) $\mathrm{nm}$.

BT-DPB: orange crystals. Yield: $209 \mathrm{mg}(0.39 \mathrm{mmol}, 71 \%) .{ }^{1} \mathrm{H} \mathrm{NMR}\left(500 \mathrm{MHz} \mathrm{CDCl}_{3}\right.$,

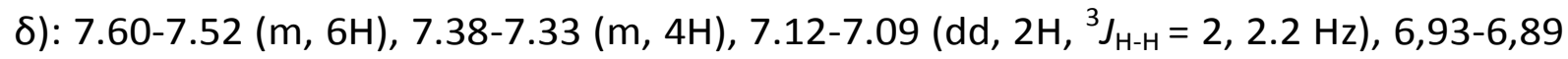
$(\mathrm{m}, 4 \mathrm{H}), 6.89-6.83\left(\mathrm{~d}, 2 \mathrm{H},{ }^{3} \mathrm{~J}_{\mathrm{H}-\mathrm{H}}=4 \mathrm{~Hz}\right), 6.56-6.52\left(\mathrm{~d}, 2 \mathrm{H},{ }^{3} \mathrm{~J}_{\mathrm{H}-\mathrm{H}}=4 \mathrm{~Hz}\right), 6.29(\mathrm{~s}, 2 \mathrm{H},=\mathrm{CH})$ ppm. ${ }^{13} \mathrm{C}\left\{{ }^{1} \mathrm{H}\right\}$ NMR $\left(125 \mathrm{MHz} \mathrm{CDCl}_{3}, \delta\right): 142.9,140.8,138.5,138.2,137.7,130.7$, 130.6, 129.8, 128.5, 127.9, 125.1, 124.4, 123.5, 123.1 ppm. HR-MS (ASAP ${ }^{+}$) m/z: calc 
for $\mathrm{C}_{32} \mathrm{H}_{23} \mathrm{~S}_{4}{ }^{+}$[BT-DPB $\left.+\mathrm{H}\right]^{+}$, 534.0604; found, 534.0599. UV-Vis (THF) $\lambda \max \left(\varepsilon\right.$, L.mol $^{-}$ $\left.{ }^{1} . \mathrm{cm}^{-1}\right)=408$ (39 700), 434 (53 400), 460 (39 100) nm.

EDOT-DPB: orange powder. Yield: $161 \mathrm{mg}$ (0.33 mmol, 60\%). ${ }^{1} \mathrm{H} \mathrm{NMR} \mathrm{(600} \mathrm{MHz,}$

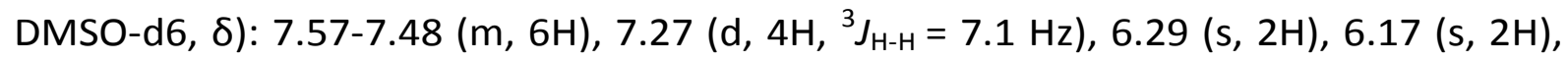
$4.05\left(\mathrm{q}, 8 \mathrm{H},{ }^{3} \mathrm{~J}_{\mathrm{H}-\mathrm{H}}=5.2 \mathrm{~Hz}, \mathrm{CH}_{2}\right) \mathrm{ppm} .{ }^{13} \mathrm{C}\left\{{ }^{1} \mathrm{H}\right\}$ NMR $(150 \mathrm{MHz}, \mathrm{DMSO}-\mathrm{d} 6, \delta): 140.8$, 140.2 , 140.1, 138.0, 130.3, 129.5, 128.4, 118.8, 115.3, 101.4, 64.6, 64.2 ppm. HR-MS $(A S A P+) \mathrm{m} / \mathrm{z}$ : calc. for $\mathrm{C}_{28} \mathrm{H}_{23} \mathrm{O}_{4} \mathrm{~S}_{2}+$ [EDOT-DPB $\left.+\mathrm{H}\right]^{+}$486.0960; found, 486.0967. UVVis (THF) $\lambda\left(\varepsilon\right.$, L. mol $\left.^{-1} . \mathrm{cm}^{-1}\right)=365$ (36 100), 383 (56 700), 405 (49 500) nm.

\section{Conclusions}

In summary, we have prepared DPBs containing electropolymerizable thienyl, bisthienyl and EDOT units through desilylation reactions of the corresponding 3,4diphenylsiloles derivatives. These three DPBs possess typical AIE/AEE characteristics with, as expected, an increase of the fluorescence when aggregated. Specifically, TDPB and EDOT-DPB probably with stronger aromatic $\mathrm{C}-\mathrm{H} / \pi$ interactions are found to be good AlEgens while BT-DPB exhibited AEE behaviour. The electrochemical properties of these DPBs also revealed for all these compounds the occurrence of electropolymerization process leading to electrogenerated polymers with low bandgaps (1.54 eV for poly(T-DPB), $1.62 \mathrm{eV}$ for poly(BT-DPB) and $1.44 \mathrm{eV}$ for poly(EDOT-DPB)). After p-doping process, UV-Visible absorption studies suggest that poly(T-DPB) and poly(EDOT-DPB) exhibit a lower conduction band than poly(BTDPB).

\section{Conflicts of interest}

There are no conflicts to declare

\section{Acknowledgements}

The authors thank the Université de Montpellier for financial support. 


\section{Notes and references}

1 J. Mei, N. L. Leung, R. T. Kwok, J. W. Lam and B. Z. Tang, Chem Rev, 2015, 115, 1171811940.

2 J. Mei, Y. Hong, J. W. Lam, A. Qin, Y. Tang and B. Z. Tang, Adv Mater, 2014, 26, 54295479.

3 Y. Hong, J. W. Lam and B. Z. Tang, Chem. Commun. (Camb), 2009, 4332-4353.

4 Y. Chen, J. W. Y. Lam, R. T. K. Kwok, B. Liu and B. Z. Tang, Mater. Horiz., 2019, 6, 428433.

5 Y. Hong, J. W. Lam and B. Z. Tang, Chem. So.c Rev., 2011, 40, 5361-5388.

6 Y. F. Wang, T. Zhang and X. J. Liang, Small., 2016, 12, 6451-6477.

7 L. Mao, Y. Liu, S. Yang, Y. Li, X. Zhang and Y. Wei, Dyes Pigm., 2019, 162, 611-623.

8 C. Zhu, R. T. K. Kwok, J. W. Y. Lam and B. Z. Tang, ACS Appl. Bio. Mater., 2018, 1, 17681786.

9 X. Lou, Z. Zhao and B. Z. Tang, Small, 2016, 12, 6430-6450.

10F. Hu, S. Xu and B. Liu, Adv. Mater., 2018, 30, 1801350.

11 Y. Zhang, Y. Wang, J. Wang and X.-J. Liang, Mater. Horiz., 2018, 5, 799-812.

12 J. Dai, X. Wu, S. Ding, X. Lou, F. Xia, S. Wang and Y. Hong, J. Med. Chem., 2020, 63, 1996-2012.

13 M. Gao and B. Z. Tang, ACS Sens., 2017, 2, 1382-1399.

14D. D. La, S. V. Bhosale, L. A. Jones and S. V. Bhosale, ACS Appl. Mater. Interfaces, $2018,10,12189-12216$.

15 L. Yan, Y. Zhang, B. Xu and W. Tian, Nanoscale, 2016, 8, 2471-2487.

16 D. Wang and B. Z. Tang, Acc. Chem. Res., 2019, 52, 2559-2570.

17X. Wei, M. J. Zhu, H. Yan, C. Lu and J. J. Xu, Chem. Eur. J., 2019, 25, 12671-12683.

18F. Rizzo and F. Cucinotta, Isr. J. Chem., 2018, 58, 874-888.

19E. Ubba, Y. Tao, Z. Yang, J. Zhao, L. Wang and Z. Chi, Chem. Asian J., 2018, 13, 31063121.

20Z. Y. Yang, Z. H. Chi, Z. Mao, Y. Zhang, S. W. Liu, J. Zhao, M. P. Aldred and Z. G. Chi, Mater. Chem. Front., 2018, 2, 861-890.

21X. R. Jia, H. J. Yu, J. Chen, W. J. Gao, J. K. Fang, Y. S. Qin, X. K. Hu and G. Shao, Chem. Eur.J., 2018, 24, 19053-19059. 
22 P. J. Shi, X. X. Zhang, Y. Liu, Y. A. Duan, Y. P. Li, Z. F. Li and T. Y. Han, Mater. Lett., 2020, 263, 127214

23 J. F. Yang, K. Z. Gu, C. X. Shi, M. Li, P. Zhao and W. H. Zhu, Mater. Chem. Front., 2019, 3, 1503-1509.

24 Y. Xie and Z. Li, Chem Asian J., 2019, 14, 2524-2541.

25Z. J. Zhao, J. W. Y. Lam and B. Z. Tang, J. Mater. Chem., 2012, 22, 23726-23740.

26Z. J. Zhao, J. W. Y. Lam and B. Z. Tang, Curr. Org. Chem., 2010, 14, 2109-2132.

27 M. Arribat, E. Rémond, S. Richeter, P. Gerbier, S. Clément and F. Cavelier, Eur. J. Org.

Chem., 2019, 2019, 2275-2281.

28Z. Zhao, B. He and B. Z. Tang, Chem. Sci., 2015, 6, 5347-5365.

29Z. Q. Guo, A. D. Shao and W. H. Zhu, J. Mater. Chem. C, 2016, 4, 2640-2646.

30Z. Guo, C. Yan and W. H. Zhu, Angew. Chem. Int. Ed, 2019, 59, 2-16.

31 W. Z. Yuan, Y. Y. Gong, S. M. Chen, X. Y. Shen, J. W. Y. Lam, P. Lu, Y. W. Lu, Z. M. Wan,

R. R. Hu, N. Xie, H. S. Kwok, Y. M. Zhang, J. Z. Sun and B. Z. Tang, Chem. Mater., 2012, 24, 1518-1528.

32Z. Ning, Z. Chen, Q. Zhang, Y. Yan, S. Qian, Y. Cao and H. Tian, Adv. Funct. Mater., 2007, 17, 3799-3807.

33 B. Wang, Y. Wang, J. Hua, Y. Jiang, J. Huang, S. Qian and H. Tian, Chem. Eur. J., 2011, 17, 2647-2655.

34 Properties of Triarylamine Derivatives with AIE and Large Two-Photon Absorbing

Cross-Sections, by Jianli Hua, He Tian and Hao Zhang, edited by Ben Zhong Tang and Anjun Qin From Aggregation-Induced Emission: Fundamentals, 2014, 169-184 35 N. Yamamoto, J. Phys. Chem. C, 2018, 122, 12434-12440.

36 A. K. Vasu, M. Radhakrishna and S. Kanvah, J. Phys. Chem. C, 2017, 121, 22478-22486. 37 Aggregation-Induced Emission of 9, 10-Distyrylanthracene Derivatives and Their Applications, by Bin Xu, Jibo Zhang and Wenjing Tian, editer by Ben Zhong Tang and Anjun Qin From Aggregation-Induced Emission: Fundamentals, 2014, 61-82

38J. B. Zhang, S. Q. Ma, H. H. Fang, B. Xu, H. B. Sun, I. Chan and W. J. Tian, Mater Chem Front, 2017, 1, 1422-1429.

39 K. C. Nicolaou, J. Y. Ramphal, N. A. Petasis and C. N. Serhan, Angew. Chem. In. Ed. Engl, 1991, 30, 1100-1116.

40S. D. Rychnovsky, Chem. Rev., 1995, 95, 2021-2040. 
41 B. J. Rawlings, Nat. Prod. Rep., 1997, 14, 335-358.

42 D. J. Faulkner, Nat. Prod. Rep., 1998, 15, 113-158.

43S. D. Rychnovsky, B. N. Rogers and T. I. Richardson, Acc. Chem. Res., 1998, 31, 9-17.

44 B. C. Ranu, S. Banerjee and A. Das, Tetrahedron Lett., 2006, 47, 881-884.

45 J. H. Barnard, J. C. Collings, A. Whiting, S. A. Przyborski and T. B. Marder, Chem. Eur. J., 2009, 15, 11430-11442.

46Y. Ezhumalai, T. H. Wang and H. F. Hsu, Org. Lett., 2015, 17, 536-539.

47Y. Zhang, H. Mao, W. Xu, J. Shi, Z. Cai, B. Tong and Y. Dong, Chem. Eur. J., 2018, 24, 15965-15977.

48 M. K. Bera, C. Chakraborty and S. Malik, J. Mater. Chem. C, 2017, 5, 6872-6879.

49S. Tavazzi, A. Camposeo, D. Pisignano and L. Silvestri, The J. Phys. Chem. C, 2014, 118, 8588-8594.

50J. Chen, B. Xu, X. Ouyang, B. Z. Tang and Y. Cao, J. Phys. Chem. A, 2004, 108, 75227526.

51 K. Baba, H. Kasai, S. Okada, H. Oikawa and H. Nakanishi, Opt.l Mater., 2003, 21, 591594.

52S. Tavazzi, L. Silvestri, L. Miozzo, A. Papagni, P. Spearman, S. lanelli, A. Girlando, A. Camposeo, M. Polo and D. Pisignano, Chemphyschem, 2010, 11, 429-434.

53 Y. Zhang, H. Xu, W. Xu, C. Zhang, J. Shi, B. Tong, Z. Cai and Y. Dong, Sci. China Chem. , 2019, 62, 1393-1397.

54 J. L. Banal, J. M. White, K. P. Ghiggino and W. W. Wong, Sci Rep., 2014, 4, 4635.

55 Y. Zhang, L. Kong, J. Shi, B. Tong, J. Zhi, X. Feng and Y. Dong, Chin. J. Chem., 2015, 33, 701-704.

56Y. Liu, J. W. Y. Lam, X. Zheng, Q. Peng, R. T. K. Kwok, H. H. Y. Sung, I. D. Williams and B. Z. Tang, Macromolecules, 2016, 49, 5817-5830.

57J. R. Clark, J. R. Griffiths and S. T. Diver, J. Am. Chem. Soc., 2013, 135, 3327-3330.

58S. Yamaguchi, T. Endo, M. Uchida, T. Izumizawa, K. Furukawa and K. Tamao, Chem. Eur. J., 2000, 6, 1683-1692.

59T. J. Brown, B. D. Robertson and R. A. Widenhoefer, J. Organomet. Chem., 2014, 758, 25-28.

60 C. M. Ting, Y. L. Hsu and R. S. Liu, Chem. Commun. (Camb), 2012, 48, 6577-6579.

61 Y. Liu, G. Zhang and H. Huang, Org. Lett., 2017, 19, 6674-6677. 
62 Y. Al-Jawaheri and M. C. Kimber, Org. Lett., 2016, 18, 3502-3505.

63E. Shirakawa, G. Takahashi, T. Tsuchimoto and Y. Kawakami, Chem. Commun., 2001, 2688-2689.

64 T. Satoh, S. Ogino, M. Miura and M. Nomura, Angew. Chem. Int. Ed Engl, 2004, 43, 5063-5065.

65T. Satoh, S. Ogino, M. Miura and M. Nomura, Angew. Chem., 2004, 116, 5173-5175.

66 A. J. Boydston and B. L. Pagenkopf, Angew. Chem. Int Ed Engl., 2004, 43, 6336-6338.

67 K. A. Wills, H. J. Mandujano-Ramírez, G. Merino, G. Oskam, P. Cowper, M. D. Jones, P.

J. Cameron and S. E. Lewis, Dyes Pigm., 2016, 134, 419-426.

68Y. Hua, S. Chang, J. He, C. Zhang, J. Zhao, T. Chen, W. Y. Wong, W. K. Wong and X.

Zhu, Chem. Eur. J., 2014, 20, 6300-6308.

69Z.-S. Wang, N. Koumura, Y. Cui, M. Takahashi, H. Sekiguchi, A. Mori, T. Kubo, A.

Furube and K. Hara, Chem. Mater., 2008, 20, 3993-4003.

70K. Amro, A. K. Thakur, J. Rault-Berthelot, C. Poriel, L. Hirsch, W. E. Douglas, S. Clément and P. Gerbier, New J. Chem., 2013, 37, 464-473.

71 F. Piron, P. Leriche, I. Grosu and J. Roncali, J. Mater. Chem., 2010, 20, 10260-10268

72 F. Larmat, J. R. Reynolds, B. A. Reinhardt, L. L. Brott and S. J. Clarson, J. Polym. Sci. A, $1997,35,3627-3636$.

73Y. Lee, S. Sadki, B. Tsuie, P. Schottland and J. R. Reynolds, Synth. Met., 2001, 119, 7778.

74S. Yamaguchi, Y. Itami and K. i. Tamao, Organometallics, 1998, 17, 4910-4916.

75 A. J. Boydston and B. L. Pagenkopf, Angew. Chem. Int. Ed Engl, 2004, 43, 6336-6338.

76C. Booker, X. Wang, S. Haroun, J. Zhou, M. Jennings, B. L. Pagenkopf and Z. Ding, Angew. Chem. Int. Ed Engl, 2008, 47, 7731-7735.

77J. S. Murray and P. Politzer, J. Mol. Model., 2019, 25, 101.

78 M. Voronkov, V. Pestunovich and Y. I. Baukov, Metalloorg. Khim, 1991, 4, 1210-1227

79V. V. Negrebetsky and Y. I. Baukov, Russ. Chem. Bull., 1997, 46, 1807-1831.

80 Kost, D.; Kalikhman, I. In The Chemistry of Organic Silicon Compounds; Rappoport, Z.;

Apeloig, Y., Eds.; Wiley: Chichester, U.K., 1998; Vol. 2, p 1339

81 M. Nishio, Phys. Chem. Chem. Phys., 2011, 13, 13873-13900.

82 Y. Zhang, H. Mao, L. Kong, Y. Tian, Z. Tian, X. Zeng, J. Zhi, J. Shi, B. Tong and Y. Dong, Dyes Pigm., 2016, 133, 354-362. 
83 J. Hwang, P. Li, M. D. Smith, C. E. Warden, D. A. Sirianni, E. C. Vik, J. M. Maier, C. J. Yehl, C. D. Sherrill and K. D. Shimizu, J. Am. Chem. Soc., 2018, 140, 13301-13307.

84 Y. Zhang, T. Han, S. Gu, T. Zhou, C. Zhao, Y. Guo, X. Feng, B. Tong, J. Bing, J. Shi, J. Zhi and Y. Dong, Chem. Eur. J. 2014, 20, 8856-8861.

85 H. Mao, Y. Li, Y. Zhang, L. Kong, Y. Tian, J. Shi, Z. Cai, B. Tong and Y. Dong, Dyes Pigm., 2020, 175, 108169.

86 T. Komatsu, D. Oushiki, A. Takeda, M. Miyamura, T. Ueno, T. Terai, K. Hanaoka, Y. Urano, T. Mineno and T. Nagano, Chem. Commun., 2011, 47, 10055-10057.

87 B. A. Griffin, S. R. Adams and R. Y. Tsien, Science, 1998, 281, 269-272.

88 H. Agnihotri, A. K. Vasu, V. Palakollu and S. Kanvah, Photochem. Photobiol. Sci., 2015, 14, 2159-2167.

89T. Han, Y. Zhang, X. Feng, Z. Lin, B. Tong, J. Shi, J. Zhi and Y. Dong, Chem. Commun., $2013,49,7049-7051$.

90 L. Li, H. Nie, M. Chen, J. Sun, A. Qin and B. Z. Tang, Faraday Discuss, 2017, 196, 245253.

91 N. Cocherel, C. Poriel, O. Jeannin, A. Yassin, J. Rault-Berthelot, Dyes Pigm. 2009, 83, 339-347.

92 P. Hapiot, C. Lagrost, F. Le Floch, E. Raoult, J. Rault-Berthelot, Chem. Mater., 2005, 17, 2003-2012.

93 Q. Bricaud, A. Cravino, P. Leriche, J. Roncali, Synth. Met., 2009, 159, 2534-2538.

94 J. Rault-Berthelot, C. Paul-Roth, C. Poriel, S. Juillard, S. Ballut, S. Drouet, G. Simonneaux, J. Electroanal. Chem. 2008, 623, 204-214.

954R. C. Rault-Berthelot Joëlle, Synth. Met., 1996, 83, 153-157.

96R. C. Rault-Berthelot Joëlle, Granger Marie-Madeleine, J. Electroanal. Chem., 1997, 436, 85-101.

97J. Roncali, Chem. Rev., 1992, 92, 711-738.

98J. Roncali, Chem Rev., 1997, 97, 173-206.

99J. Roncali, P. Blanchard, P. Frère, J. Mater. Chem., 2005, 15, 1589-1610.

100 G. A. Sotzing, J. R. Reynolds, P. J. Steel, Chem. of Mater., 1996, 8, 882-889.

101 G. Zotti, G. Schiavon, S. Zecchin, L. Groenendaal, Chem. Mater., 1999, 11, 36243628. 
102 G. A. Sotzing, J. L. Reddinger, A. R. Katritzky, J. Soloducho, R. Musgrave, J. R. Reynolds, P. J. Steel, Chem. Mater., 1997, 9, 1578-1587.

103 C. Xia, R. C. Advincula, A. Baba, W. Knoll, Langmuir., 2002, 18, 3555-3560.

104 S. S. Zhu and T. M. Swager, J. Am. Chem. Soc., 1997, 119, 12568-12577.

105 K. M. de Silva, E. Hwang, W. K. Serem, F. R. Fronczek, J. C. Garno and E. E. Nesterov, ACS Appl. Mater. Interfaces, 2012, 4, 5430-5441.

106 M.-M. Duvenhage, M. Ntwaeaborwa, H. G. Visser, P. J. Swarts, J. C. Swarts and H. C. Swart, Opt. Mater., 2015, 42, 193-198.

107 R. Schlaf, P. G. Schroeder, M. W. Nelson, B. A. Parkinson, C. D. Merritt, L. A. Crisafulli, H. Murata and Z. H. Kafafi, Surf. Sci., 2000, 450, 142-152 